\title{
GFORSETI
}

Forseti. Revista de Derecho. Volumen 10, № 14, Lima, 2021, pp. 72 - 110

\section{Dos Siglos Sin Ti: La falta de un verdadero catastro en el Perú y sus consecuencias}

\author{
Rodrigo Zaldívar Del Águila* \\ Valeria Duffóo Sánchez**
}

\begin{abstract}
Resumen. - Poco se habla sobre la falta de un - verdadero - catastro predial en el Perú, aunque mucho se habla sobre la gran cantidad de problemas que tiene el país en parte causado por su ausencia: retrasos en proyectos de infraestructura, superposiciones registrales, falta de planeamiento territorial, baja recaudación tributaria municipal, entre otros. Este artículo pretende poner de relieve la situación catastral del país, a dos centenas de su independencia, y ofrecer recomendaciones para poder contar con un verdadero catastro de predios.
\end{abstract}

Abstract. - Not much is talked about the lack of a - real - land cadastre in Peru, although much is said about the problems caused by its absence: delays in infrastructure projects, registry file overlaps, lack of territorial planning, low municipal tax collection, among others. This article intends to portray the country's cadastral situation, two centuries from its independence, and offer recommendations in order to be able to count with a real land cadastre.

Palabras claves. - Catastro - Gestión de Predios - Propiedad Predial - Infraestructura - Registro de Predios - Gestión Pública.

Keywords. - Cadastre - Land Management - Real Property - Infrastructure - Land Registry Public Administration.

\footnotetext{
Magister en Derecho por la Universidad de Columbia (LL.M.). Abogado con mención Summa Cum Laude por la Pontifica Universidad Católica del Perú (PUCP), con estudios en London School of Economics y la Universidad Carlos III de Madrid. Becario por la International Bar Association y profesor adjunto en la PUCP.

** Candidata al Máster en Políticas Públicas de la Universidad Nacional of Singapur. Abogada con mención Magna Cum Laude por la Pontifica Universidad Católica del Perú (PUCP). Consultora de la Superintendencia Nacional de los Registros Públicos (SUNARP) y del Ministerio de Transportes y Comunicaciones (MTC). Becaria por BadenWurtemberg:Baden-Württemberg-Stipendium en Alemania y profesora adjunta en la Universidad de Piura y la PUCP.
} 


\section{Introducción}

En octubre del año 2018, el Estado Peruano entregó la totalidad de terrenos (280 hectáreas) necesarios para realizar la ampliación del Aeropuerto Internacional Jorge Chávez. A pesar de obligarse a entregarlos en el plazo de 1 año, el Estado demoró 18 años ${ }^{1}$.

De acuerdo con la exposición de motivos del Decreto de Urgencia No. 018-2019, la causa más frecuente del retraso en proyectos de inversión está relacionada con la demora en la entrega de terrenos, incluyendo liberación de cargas, descoordinaciones con la zonificación y en general, con poder entregar al concesionario un título habilitante para poder iniciar las obras ${ }^{2}$. Este retraso se traduce en una serie de laudos arbitrales en contra del Estado en arbitrajes ante el CIADI, donde se le ordena pagar una compensación al inversionista por dicho retraso, compensación que es pagada últimamente por todos los contribuyentes.

Lo anterior es un ejemplo notorio que demuestra cómo el Estado no ha sido capaz de contar con un método que le permita gestionar predios rápidamente. Ello se debe a que no cuenta con un sistema que le permita identificar los predios - y a sus propietarios - dentro del territorio nacional de manera eficiente, lo cual tiene un impacto en diversas actividades y situaciones.

Evidentemente, no se trata de una tarea de fácil solución. Cinco presidentes estuvieron al mando del país durante la demora en la entrega de terrenos para la ampliación del Aeropuerto Internacional Jorge Chávez y ninguno pudo implementar medidas efectivas para acelerar la entrega ${ }^{3}$. En realidad, no existe una fórmula o método mágico que permita al Estado entregar terrenos rápidamente. La solución a estos problemas, y a muchos otros, reside en contar con un instrumento de gestión territorial adecuado - con un catastro.

A pesar de que existe una Ley de Catastro en el país, y un Sistema Nacional de Catastro Predial, no existe realmente un catastro a nivel nacional. Lo que hay son varios catastros, gestionados por diferentes entidades, que cumplen funciones diferentes. A la fecha, sólo cinco municipalidades cuentan con un catastro que cumpla con las actuales normas catastrales. Ello no permite al Estado contar con un instrumento capaz de identificar claramente los predios en su territorio, generando una serie de problemas de todo tipo, no limitándose a retrasos de proyectos de inversión.

1 Redacción Gestión. “Luego de 18 años y cuatro presidentes, el Ejecutivo entrega terrenos para ampliar el Jorge Chávez". Diario Gestión. Lima, 2018. Consulta realizada el día 11 de julio de 2021 en: https://gestion.pe/economia/luego-18-anos-cuatro-presidentes-ejecutivo-entrega-terrenosampliar-jorge-chavez-248027-noticia/

2 Exposición de motivos del Decreto de Urgencia 018-2019, pp. 34. Consulta realizada el día 11 de julio de 2021 en: http://spij.minjus.gob.pe/Graficos/Peru/2019/Noviembre/28/EXP-DU-0182019.pdf

3 Aunque el quinto presidente, Martín Vizcarra, estuvo en el cargo tan solo 7 meses al momento de realizar la entrega de terrenos. 
El 28 de julio de este año el Perú celebra el bicentenario de su independencia y como parte de este acontecimiento, es importante poner de relieve los problemas que aún aquejan al país y plantear soluciones al respecto, de modo que se pueda intentar tener un país - y un Estado - moderno y eficiente. Contar con un verdadero catastro resulta indispensable para este fin.

\section{Concepto de Catastro}

Antes de abordar la discusión sobre el catastro en el Perú, es conveniente establecer qué se entiende por el concepto de catastro. La palabra 'catastro' viene del griego "Katàotíxov' que significa "registro" o "lista", tratándose pues de un "control administrativo en el que se registraba la riqueza de un territorio en general" 4 . Si bien de la definición no consta que se tratara de la riqueza relativa a la propiedad predial exclusivamente, debido a la importancia de mantener un registro de la tierra en comparación a otros bienes comprendidos en el patrimonio total de un estado, ya sea por razones impositivas o de soberanía, se entiende que se trataba de un registro referido a la tierra, y es así como se interpreta hasta el día de hoy5.

En la actualidad, la Real Academia Española (RAE) define el catastro como un "censo y padrón estadístico de las fincas rústicas y urbanas"6, aproximándose más a una definición que engloba la riqueza predial y basado en la estadística, yendo más allá de una simple lista o registro. A nivel normativo en Perú, en el Reglamento de la Ley No. 28294 se define al catastro como “ (...) el inventario físico de todos los predios que conforman el territorio nacional, incluyendo sus características físicas, económicas, usos, infraestructura, equipamiento y derechos inscritos o no"7.

Una definición más completa y holística la podemos encontrar en la Edición 9a de la revista "Land", donde se define al sistema catastral como:

"El núcleo de las funciones de administración de la tierra, incluyendo la administración y gestión de la tenencia de la tierra, su valor, su uso y desarrollo. Se trata del motor de cualquier sistema de administración de tierras, que apuntala la capacidad del país de brindar desarrollo sostenible. Los sistemas catastrales producen información catastral, requerida para hacer e implementar diferentes decisiones sobre la tierra, encapsulan la ubicación de las parcelas, definen linderos y proporcionan el tamaño de las parcelas. Todo ello es pieza fundamental de información para los

4 NEIRA REIMER, José Antonio. “Problemática del Impuesto Predial desde la Perspectiva del Catastro en el Perú" En: Gestión Descentralizada. Lima, 2011, pp. D2. Consulta realizada el día 11 de julio de 2021 en: http://www2.congreso.gob.pe/sicr/cendocbib/con3_uibd.nsf/520637E37796ADC8052579B500 63A1DF/\$FILE/tribmuni_11_01.pdf

5 Idem

6 Definición establecida por la Real Academia Española. Consulta realizada el día 11 de julio de 2021 en: https:/ / dle.rae.es/catastro

7 Artículo 3e) del Decreto Supremo 005-2006-JUS 
procedimientos de asignación de tierras, valuación de las propiedades y reducción de los conflictos y litigios relacionados con la tierra"8.

En sencillo, el catastro es un inventario de los predios que existen en el país. Permite a quien accede al mismo, un detalle sobre las características del predio en cuestión. Asimismo, con el avance de la tecnología, el catastro pasó de ser un simple registro o lista de riqueza territorial a ser una figura que más se aproxima a una cartografía digital detallada, que forma parte de un sistema de gestión administrativa.

Es importante recalcar el carácter administrativo del catastro. El catastro surge como una herramienta a disposición de la administración estatal para cuantificar la riqueza inmobiliaria de un territorio con la finalidad de facilitar la recaudación tributaria9. Esto es lo que se le denomina el catastro administrativo, cuya función es principalmente fiscal. Desde civilizaciones atrás, los Estados recaudan dinero del público mediante tributos a las propiedades. Para asegurar una recaudación más efectiva, es necesario contar con un catastro de modo que se pueda cuantificar la obligación tributaria en función al área y ubicación de los predios.

Distinto es el catastro visto desde su función jurídica, cuya finalidad no es asegurar una recaudación más efectiva, sino publicitar los derechos que las personas tienen sobre los predios. Con el paso del tiempo y con la sofisticación del derecho civil y el intercambio de bienes entre particulares, las administraciones estatales expandieron las funciones del catastro, transformándolo en un registro de inmuebles, una herramienta para otorgar mayor seguridad al tráfico inmobiliario ${ }^{10}$. Es así como surgen los registros de predios en todo el mundo y que, en el caso de Perú, es manejado por la Superintendencia Nacional de Registros Públicos (SUNARP).

Así, cuando uno habla de "catastro" hoy en día, se refiere al catastro en su función administrativa o de gestión (no únicamente fiscal, sino también social, ambiental o cualquier materia que pueda ayudar al estado a planificar su territorio). Por otro lado, cuando uno quiere hablar del catastro en su función jurídica, se refiere al "registro de predios".

Si bien el catastro y el registro de predios cumplen funciones con relación a predios, se ocupan de ámbitos distintos. La abogada y ex Superintendente de SUNARP Angélica Portilla esboza la diferencia principal de la siguiente manera:

8 Traducción libre de Chekole, Solomon D.; de Vries, Walter T.; Shibeshi, Gebeyehu B. 2020. "An Evaluation Framework for Urban Cadastral System Policy in Ethiopia". Land 9, no. 2: 60. Consulta realizada el día 11 de julio de 2021 en: https:/ / doi.org/10.3390/land9020060

9 NEIRA REIMER, José Antonio. "Problemática del Impuesto Predial desde la Perspectiva del Catastro en el Perú". Gestión Descentralizada. Lima, 2011, pp. D2. Consulta realizada el día 11 de julio de 2021 en: http://www2.congreso.gob.pe/sicr/cendocbib/con3_uibd.nsf/520637E37796ADC8052579B500 63A1DF/\$FILE/tribmuni_11_01.pdf

10 Idem 
"El Registro (de Predios) tiene como finalidad esencial garantizar la protección de los derechos reales inscritos $y$, por ende, brindar seguridad jurídica al tráfico inmobiliario. Por su parte, el Catastro nació para suministrar al Estado información relevante sobre la localización geográfica de los inmuebles y sus características que permitiera, en muchos casos, la recaudación eficaz de los tributos inmobiliarios" 11.

Por tanto, no se deben confundir ambas instituciones. Si una persona adquiere un predio y desea inscribir su compra, lo va a hacer en el registro de predios, que otorga publicidad registral y es el único registro capaz de otorgar seguridad jurídica a dicha adquisición. La inscripción en algún catastro que tenga una indicación del titular catastral no provee seguridad jurídica.

La relación catastro-registro de predios no es uniforme en el mundo. Algunos países integran el catastro y el registro de predios bajo una sola entidad, mientras otros los mantienen como entidades separadas, con distintos grados de interconexión. En las siguientes secciones se tratará en mayor detalle la relación catastro-registro en el Perú.

\section{Recuento histórico}

Antes de realizar un recuento histórico, debemos aclarar que la historia del catastro en el Perú es compleja y particular, pues no podemos hablar de un catastro en singular, ya que no existe un solo catastro, sino varios que cumplen distintas funciones para las entidades que lo manejan. Esta pluralidad de competencias en materia catastral surgió a raíz de iniciativas y necesidades específicas de los distintos sectores económicos del país (ej. minería y agricultura), dificultando la creación de un catastro nacional, uniforme y multifinalitario ${ }^{12}$. Es por ello que este recuento histórico va a estar segmentado por tipo de catastro hasta llegar a la Ley 28294.

El catastro, al ser un inventario de la riqueza predial dentro de un territorio, cumplía una función de índole fiscal. Así, desde la época de los antiguos imperios, tanto nobles como plebeyos que eran dueños de tierras, debían de cumplir con pagar tributos al Estado, y este se medía en función a la riqueza (o patrimonio) que cada uno poseía.

Perú no fue la excepción. La existencia de un catastro en el país (posterior a la Independencia de España) se puede remontar hasta el año 1856, cuando las municipalidades de aquel entonces comienzan a recopilar datos para la formación de sus catastros. Casi un siglo después se le otorgó el manejo de la Planoteca Nacional al Departamento de Catastro Nacional de la Superintendencia General

11 PORTILlO FLORES, Angélica María. “El Catastro en el Perú: estudio teórico, jurídico y de gestión”, Primera Edición. Palestra Editores, Lima, 2009, pp. 52.

12 Ibid., pp. 161. 
de Contribuciones. La Planoteca Nacional era el conjunto de planos públicos del país, e incluía tanto los predios rústicos como los urbanos ${ }^{13}$.

\section{i. Catastro rural (o de posesiones informales en zonas rurales)}

Los inicios de un catastro de alcance nacional (aunque sectorial) se dan en el ámbito rural como parte de los esfuerzos de la Reforma Agraria. De acuerdo con la Primera Disposición Transitoria Decreto Ley 17716 de fecha 24 de junio de 1969, comúnmente conocido como la Ley de Reforma Agraria, se estableció que la Dirección de Catastro formará parte de la Dirección General de Reforma Agraria y Asentamiento Rural.

La Dirección de Catastro elaboró el catastro de tierras agrícolas, que sirvió para planificar la expropiación y colectivización de parcelas agrícolas a favor de los trabajadores agrícolas. Este catastro cumplió su función administrativa, pues logró centralizar las políticas agrarias y otorgarles a los beneficiarios de las expropiaciones un "título catastral" sobre la tierra que poseían.

Cabe recalcar que dicho catastro rural no era un catastro jurídico. El Registro de Predios era en ese entonces, y lo sigue siendo hoy en día, aquel registro que podía dar fe y seguridad jurídica a las transferencias de propiedad predial otorgando publicidad, presunción de validez y oponibilidad frente a terceros. Si bien aquel título catastral (o la resolución que ordena la expropiación a favor del poseedor) podía ser usado como prueba de propiedad, al no estar inscrita en el Registro de Predios, la titularidad no estaba protegida por la publicidad que otorga el mismo. A pesar de ello, muchos de los beneficiarios de las expropiaciones no inscribieron su título en el Registro de Predios. Por tanto, quedó pendiente la "formalización" de dichas propiedades, entendiéndose formalizada una propiedad cuando además de haberla adquirido civilmente, es inscrita en el registro correspondiente.

Por ello, en 1992, mediante Decreto Ley No. 25902 se creó el Proyecto Especial de Titulación de Tierras y Catastro Rural (PETT). El PETT se encargaba de gestionar el catastro rural, y llevar a cabo el saneamiento físico-legal de tierras rústicas, eriazas y de los territorios de comunidades campesinas, con el objetivo de inscribir las titularidades respectivas en el Registro de Predios. En el año 2007, mediante Decreto Supremo 005-2007-VIVIENDA, el PETT fue absorbido por el Organismo de Formalización de la Propiedad Informal (COFOPRI), quien pasó a gestionar el catastro rural.

Posteriormente, mediante Decreto Supremo 018-2014-VIVIENDA el catastro rural fue transferido al Ministerio de Agricultura (Minagri), transferencia que fue completada el 2016. En este último caso se especifica que el Minagri será el ente

13 PAREDES LOPES, Nilton y ERBA, Diego Alfonso. “El Catastro Territorial en la República del Perú" En: "El Catastro Territorial en América Latina y el Caribe", Lincoln Institute of Land and Policy, Cambridge, MA, 2008. pp. 320. Consulta realizada el día 11 de julio de 2021 en: https://www.lincolninst.edu/sites/default/files/pubfiles/el-catastro-territorial-americalatina-full.pdf 
rector del catastro rural, es decir, no va a generar un catastro, sino a gestionarlo. Son los Gobiernos Regionales los que, de acuerdo con el inciso n) del artículo 51 de la Ley Orgánica de Gobiernos Regionales, se encargan del saneamiento físicolegal de la propiedad agraria. El Decreto Supremo 018-2014 antes aludido expresa que los Gobiernos Regionales emitirán los planos necesarios para formalizar la propiedad rural.

En marzo de 2021 fue promulgada la Ley 31145, con el objetivo de estandarizar en una sola norma el marco legal para la formalización de predios rurales y el saneamiento físico-legal de los mismos por parte de los Gobiernos Regionales, manteniendo al Minagri como ente rector. Si bien aún está pendiente la reglamentación de dicha ley ${ }^{14}$, la misma constituye un esfuerzo de simplificación normativa que se debe de resaltar, pues consolida en una norma los diferentes procedimientos a cargo de los Gobiernos Regionales en relación a la materia y derogando las diferentes normas que se promulgaron a lo largo de los años, como parte del proceso de transferencia de dichas funciones a aquellos.

Por lo tanto, quienes generan el catastro rural, el cual tiene el fin de formalizar tierras agrícolas, son los Gobiernos Regionales. A su vez, el Minagri sirve de ente rector de este catastro rural, de modo que guía y emite directivas que los Gobiernos Regionales deben seguir.

\section{ii. Catastro urbano (o de posesiones informales en zonas urbanas)}

El catastro de áreas urbanas en proceso de formalización, también llamado Catastro Urbano Nacional15, se encuentra a cargo de COFOPRI. Esta institución fue creada en 1996 mediante Decreto Legislativo No. 803 con el fin de formalizar las posesiones informales (asentamientos humanos, urbanizaciones populares, etc.) que se encuentran en propiedad estatal.

Para ello, desde aquella época hasta el presente, COFOPRI administra un catastro de posesiones informales ya que, como parte de su procedimiento de formalización, realiza un saneamiento técnico-legal del área a formalizar. Dicho catastro es indispensable para su labor formalizadora y versa sobre las posesiones en proceso de formalizar que se encuentran en propiedad estatal.

\section{iii. Catastro municipal}

El catastro de los demás predios, que no son parte de posesiones informales, y que por tanto no recaen dentro de las competencias de COFOPRI (en posesiones urbanas) o de los Gobiernos Regionales y el MINAGRI (en posesiones rurales), son gestionados por las municipalidades de acuerdo con la Ley Orgánica de Municipalidades.

De acuerdo con el artículo 79.3.3. de la Ley 27972, actual Ley Orgánica de Municipalidades, los gobiernos locales son los encargados de gestionar un catastro

14 A la fecha de remisión de este artículo.

15 De acuerdo con el Decreto Legislativo 1365. 
para su territorio ${ }^{16}$. Esto último implica que debería existir un catastro predial en cada uno de los 1,678 distritos y 196 provincias $^{17}$. Sin embargo, hasta el año 2017, un $55.2 \%$ de las municipalidades cuenta con algún tipo de catastro y de esos, solo el 20.2\% (11.15\% del total) ha realizado una actualización del mismo18.

Con relación a Lima Metropolitana, en 1989 se creó el Instituto Catastral de Lima (ICL), encargado de "brindar servicios catastrales y de cartografía a la (Municipalidad), administrando y manteniendo la base catastral del Cercado de Lima"19. Este fue un ambicioso plan donde se procuró usar la tecnología de aquel entonces para graficar el catastro del Cercado de Lima. Hoy en día el ICL es un organismo público descentralizado de la Municipalidad Metropolitana de Lima (MML) que ofrece servicios de levantamiento, actualización y mantenimiento del catastro en Lima Metropolitana y a nivel nacional20, siendo un organismo de gestión y apoyo a los gobiernos locales, principalmente a la MML.

\section{iv. $\quad$ SUNARP - Base Gráfica Registral}

Los registros de predios fueron concebidos como registros alfanuméricos, es decir, ubicaban e identificaban a los predios con letras y números. Por tanto, cada predio contaba únicamente con una indicación literal de su ubicación que se inscribe como su dirección registral (calle, número, interior, colindantes, etc.). Al no contar con datos gráficos para identificar al predio, la identificación no era del todo exacta, especialmente en áreas rurales donde la extensión de los predios suele ser mayor, menos geométrica y se cuenta con menos elementos que permitan identificar los límites de la propiedad.

Los primeros esfuerzos para introducir cartografía en el registro de predios se dan en el año 1989. Mediante Decreto Supremo 02-89-JUS, se determina que, para toda inscripción de primera de dominio o subdivisión de predios urbanos, que estén ubicadas en zonas catastradas o en proceso de levantamiento catastral (es decir, donde alguna entidad, sea municipal u otra, haya o esté levantando un catastro);

16 Las Municipalidades Distritales realizan el catastro sobre el área de su jurisdicción, mientras las Municipalidades Provinciales lo hacen en el área que tienen competencia exclusiva (ej. la Municipalidad Metropolitana de Lima (considerada municipalidad provincial) maneja el catastro del Cercado de Lima, pero no de los distritos de la capital, pues estos cuentan con sus propios municipios distritales).

17 INEI, Registro Nacional de Municipalidades. Consulta realizada el día 11 de julio de 2021 en: http://m.inei.gob.pe/prensa/noticias/municipalidades-del-pais-brindaran-informacion autodiligenciada-para-actualizar-el-registro-nacional-de-municipalidades-202012179/\#: : :text=El\%20Instituto\%20Nacional \%20de\%20Estad\%C3\%ADstica,mil $\% 20740 \% 20$ muni cipalidades $\% 20 \mathrm{de} \% 20$ centros

18 Instituto Peruano de Economía. "El Catastrófico Catastro Peruano". Informe de El Comercio IPE. Consulta realizada el día 11 de julio de 2021 en: https://www.ipe.org.pe/portal/elcatastrofico-catastro-peruano/

19 PAREDES LOPES, Nilton y ERBA, Diego Alfonso. “El Catastro Territorial en la República del Perú" En: "El Catastro Territorial en América Latina y el Caribe", Lincoln Institute of Land and Policy, Cambridge, MA, 2008. pp. 324. Consulta realizada el día 11 de julio de 2021 en: https://www.lincolninst.edu/sites/default/files/pubfiles/el-catastro-territorial-americalatina-full.pdf

20 Instituto Catastral de Lima. Consulta realizada el día 11 de julio de 2021 en: http://www.icl.gob.pe/quienes-somos/servicios-que-brinda 
se deberá presentar copia del plano catastral y del código catastral. Esto sirvió para identificar mejor las nuevas inscripciones de predios en aquellas zonas, sin embargo, su alcance fue limitado pues la mayoría de las zonas del país no contaba con un catastro.

Es con el Reglamento de Inscripción del Registro de Predios del año 2003, que se establece la obligatoriedad de contar con informes de la misma área de catastro de SUNARP para inscribir actos que impliquen la modificación del predio inscrito o para inmatricular un predio (es decir, para incorporar por primera vez un predio al registro).

Esta "área de catastro" es un área interna de las oficinas de SUNARP, que desarrollan la Base Gráfica Registral. Esta es a su vez un "sistema de información estructurada para el almacenamiento, análisis y gestión de diversa información gráfica georreferenciada y alfanumérica que tiene como objetivo central identificar de manera unívoca la ubicación georreferenciada de cada predio inscrito" 21 .

El objetivo, por tanto, es plasmar en esta base gráfica, la información alfanumérica o literal del Registro de Predios. Para ello, el área de catastro de SUNARP utiliza planos y cartografías de diversas instituciones, como COFOPRI. Ello implica que la oficina de catastro de SUNARP no realiza un levantamiento catastral ellos mismos, por lo que se le ha criticado el autodenominarse "área de catastro" 22.

Por otro lado, la misma SUNARP aprobó la Resolución del Superintendente Nacional de los Registros Públicos No 063-2020-SUNARP-SN el 29 de mayo de 2020 mediante la cual se aprobó el Convenio de Adhesión de Colaboración Interinstitucional para el acceso de las entidades del Poder Ejecutivo y los Gobiernos Regionales a la información contenida en la Base Gráfica Registral a través del cual se precisó que la Sunarp no es una entidad generadora de catastro, y que la información contenida en la base gráfica registral está referida a la información reconstruida a partir de los datos gráficos y alfanuméricos que obran en los títulos archivados de los predios inscritos en el Registro de Predios; por lo que tiene una naturaleza netamente referencial.

\section{v. Catastro minero, de áreas naturales protegidas y otros denominados catastros}

El Catastro Minero tiene sus orígenes en 1950, cuando se promulga, mediante Decreto Ley No. 11357, el Código de Minería. Este cuerpo normativo crea a su vez, el Registro de Concesiones y Derechos Mineros el cual atribuye un "carácter imperativo a la inscripción de las concesiones y de los actos y contratos permitidos por ley"23. Posteriormente, se cambia su denominación a Registro Público de Minería, el cual contaba con una Dirección General de Catastro y era manejado por

21 PORTILlO FLORES, Angélica María "El Catastro en el Perú: estudio teórico, jurídico y de gestión”, Primera Edición. Palestra Editores, Lima, 2009, pp. 76.

22 Ibid., pp. 87.

23 MORALES DASSO, José Miguel y MORANTE BRIGNETI, África. “Aciertos y Debilidades de la Legislación Minera Actual”. En: Revista de Derecho Administrativo No. 8, 2009, pp. 138. 
el Instituto Nacional de Concesiones y Catastro Minero (INACC). Hoy en día, el Catastro Minero es gestionado por el Instituto Geológico Minero y Metalúrgico (INGEMMET), tras haber absorbido al INACC, y está adscrito al Ministerio de Energía y Minas.

La principal función del Catastro Minero es asegurar que no exista superposición de petitorios o derechos mineros, es decir, que más de una empresa concesionaria no cuente con la titularidad para explorar o explotar derechos mineros sobre la misma área. Es un mecanismo de ordenamiento de la actividad minera, y permite al Ministerio de Energía y Minas, saber qué petitorios mineros existen, quién los maneja y donde están ubicados.

El Catastro Oficial de Áreas Naturales Protegidas es gestionado por el Servicio Nacional de Áreas Naturales Protegidas (SERNANP), adscrito al Ministerio del Ambiente. Este catastro tiene su origen en la Ley No. 26834 y su objetivo es llevar el registro de las áreas naturales protegidas que existen en el país, de modo que se pueda facilitar su vigilancia y protección.

Como se puede ver, estos denominados catastros no versan sobre predios sino sobre otros bienes: concesiones mineras y áreas naturales protegidas. En estricto, se tratan de bases de datos georreferenciadas que surgen, más bien, por la ausencia de un catastro predial, de alcance nacional y multifinalitario, que contenga, además del detalle sobre los predios, los derechos mineros y las áreas naturales protegidas del territorio catastrado ${ }^{24}$.

Esto es importante de recalcar, pues en estas bases gráficas, no se tiene realmente la información sobre las características de los predios que rodean los respectivos derechos mineros o áreas protegidas. Su funcionalidad es estrictamente limitada a su sector, no es una herramienta que permita, por sí sola, gestionar el territorio.

Adicionalmente a los ya mencionados, existen otras entidades que también realizan actividad catastral.

El Instituto Geográfico Nacional (IGN) es un organismo adscrito al Ministerio de Defensa y su función es elaborar y actualizar la Cartografía Básica Oficial del Perú, de acuerdo con la ley de su creación, Ley No. 27292. Proporciona a las entidades públicas y privadas la cartografía que requieran, pero únicamente para fines del desarrollo de la Defensa Nacional25.

Desde la promulgación de la Ley 28294, el IGN participa en los procesos de generación de la cartografía catastral, al ser su red geodésica el marco de referencia de la actividad del ordenamiento catastral. Es decir, establece los requisitos

24 PORTILlO FLORES, Angélica María "El Catastro en el Perú: estudio teórico, jurídico y de gestión", Primera Edición. Palestra Editores, Lima, 2009, pp. 86.

25 Plataforma digital única del Estado Peruano. Consulta realizada el día 11 de julio de 2021 en: https://www.gob.pe/4111-instituto-geografico-nacional-que-hacemos 
técnicos que deberán adoptar las demás entidades generadoras de catastro en la elaboración de sus respectivos catastros.

La Superintendencia Nacional de Bienes Estatales (SBN) es un organismo adscrito al Ministerio de Vivienda y es el ente encargado de supervisar y gestionar los bienes del Estado. Como parte de su labor, se encarga de gestionar el Sistema de Información Nacional de Bienes Estatales (SINABIP), el cual incluye información catastral sobre los mismos.

Finalmente, el Ministerio de Cultura tiene a su cargo el Sistema de Información Geográfica de Arqueología (SIGDA), el cual contiene un catastro de monumentos arqueológicos prehispánicos a nivel nacional.

\section{vi. Tabla resumen}

El entramado institucional de los catastros en el Perú, y las entidades que lo rigen, puede ser resumido en la siguiente tabla:

\begin{tabular}{|c|c|c|}
\hline Institución & Rama de gobierno & Tipo de catastro \\
\hline Municipalidades & Gobiernos locales & $\begin{array}{l}\text { Catastro de predios } \\
\text { municipal }\end{array}$ \\
\hline Gobiernos Regionales & Gobiernos locales & $\begin{array}{l}\text { Catastro de } \\
\text { posesiones informales } \\
\text { a formalizar (rural) }\end{array}$ \\
\hline COFOPRI & $\begin{array}{l}\text { Gobierno Central } \\
\text { (Ministerio Vivienda) }\end{array}$ & $\begin{array}{l}\text { Catastro de } \\
\text { posesiones informales } \\
\text { a formalizar (urbano) }\end{array}$ \\
\hline $\begin{array}{l}\text { Ministerio de } \\
\text { Agricultura }\end{array}$ & Gobierno Central & $\begin{array}{l}\text { Catastro de } \\
\text { posesiones informales } \\
\text { a formalizar (rural) } \\
\text { (ente rector) }\end{array}$ \\
\hline INGEMMET & $\begin{array}{l}\text { Gobierno Central } \\
\text { (Ministerio de Energía y } \\
\text { Minas) }\end{array}$ & $\begin{array}{l}\text { Catastro de derechos } \\
\text { mineros }\end{array}$ \\
\hline SERNANP & $\begin{array}{l}\text { Gobierno Central } \\
\text { (Ministerio del Ambiente) }\end{array}$ & $\begin{array}{l}\text { Catastro de áreas } \\
\text { naturales protegidas }\end{array}$ \\
\hline SUNARP & $\begin{array}{l}\text { Gobierno Central } \\
\text { (Ministerio de Justicia) }\end{array}$ & $\begin{array}{l}\text { Base Gráfica Registral } \\
\text { del Registro de } \\
\text { Predios }\end{array}$ \\
\hline
\end{tabular}




\begin{tabular}{|l|l|l|}
\hline IGN & $\begin{array}{l}\text { Gobierno Central } \\
\text { (Ministerio de Defensa) }\end{array}$ & $\begin{array}{l}\text { Cartografía Básica } \\
\text { Oficial del Perú }\end{array}$ \\
\hline SBN & $\begin{array}{l}\text { Gobierno Central } \\
\text { (Ministerio Vivienda) }\end{array}$ & $\begin{array}{l}\text { Catastro de bienes } \\
\text { estatales (SINABIP) }\end{array}$ \\
\hline Ministerio de Cultura & Gobierno Central & $\begin{array}{l}\text { Catastro de } \\
\text { monumentos } \\
\text { arqueológicos } \\
\text { prehispánicos }\end{array}$ \\
\hline
\end{tabular}

Elaboración: Propia

\section{vii. Ley de Catastro}

Como se ha podido apreciar, la historia del catastro en el Perú no ha sido uniforme ni centralizada. Diversas entidades del Gobierno Central y las más de 1,600 municipalidades distritales y provinciales han estado encargadas de elaborar el catastro para su sector o jurisdicción.

"Estos catastros han actuado como compartimentos estancos sin eficaces relaciones de coordinación y colaboración y, por ende, han manejado distintos estándares, procesos técnicos, sistemas cartográficos e informáticos, lo que ha generado información catastral no uniforme e inconsistente, a nivel nacional" 26.

Este desorden catastral motivó al Estado a crear mayores relaciones de coordinación y colaboración entre las entidades, lo cual llevó a la promulgación de la Ley No. 28294 - Ley que crea el Sistema Nacional Integrado de Catastro y su vinculación con el Registro de Predios (LSNC) en el año 2004.

El objetivo de la LSNC, conforme a su artículo $1^{\circ}$, es crear el Sistema Nacional Integrado de Catastro Predial (SNCP) con el objeto de "regular la integración y unificación de los estándares, nomenclatura y procesos técnicos de las diferentes entidades generadoras de catastro en el país" así como establecer su vinculación con el Registro de Predios administrado por SUNARP. El SNCP cuenta con un Consejo Nacional de Catastro, una Secretaría Técnica y con Comisiones Consultivas.

Como ya se mencionó, la LSNC intentó uniformizar los estándares de producción cartográfica, rigiéndose por los estándares del IGN. Esto permitió que, en adelante, los catastros producidos por las distintas entidades generadoras no utilicen su propia tecnología y estándares, sino se adecúen a las del IGN para de esta manera poder facilitar su integración en un catastro de predios a nivel nacional.

26 PORTILlO FLORES, Angélica María “El Catastro en el Perú: estudio teórico, jurídico y de gestión”, Primera Edición. Palestra Editores, Lima, 2009, pp. 62. 
La ventaja de lo que se plantea, radica en que el SNCP permite un intercambio de información entre las entidades generadoras del catastro. En consecuencia, el $\mathrm{SNCP}$, al recibir la información, la registra en su Base de Datos Catastrales (BDC), cuya función sería en el tiempo agrupar toda la información catastral existente.

Asimismo, la vinculación entre el SNCP y el Registro de Predios será con el Código Único Catastral (CUC), generado por las municipalidades y será de obligatoria inscripción ${ }^{27}$ pues se deberá usar el CUC en todos los documentos relativos al predio 28 .

Sin embargo, hasta la fecha, 17 años después de la publicación de la Ley de Catastro y 15 años después de la publicación de su reglamento, no se ha implementado ni la BDC, ni la vinculación con el Registro de Predios. La intención de crear un catastro de predios multifinalitario se ha quedado en el aire. La norma se encuentra publicada y vigente, pero no se ha tenido la voluntad política ni administrativa de implementarla.

A la fecha, el SNCP solamente ha emitido la conformidad de zona catastrada ${ }^{29}$ a los distritos de Miraflores ${ }^{30}$, San Isidro ${ }^{31}$ (ambos en 2012), San Jerónimo de Cusco ${ }^{32}$, Los Olivos $^{33}$ (ambos en 2014) y recientemente del Cercado de Lima ${ }^{34}$ (2020). Por tanto, esas son las únicas municipalidades cuyo catastro ha sido validado y que forman parte del SNCP.

A consecuencia de ello, el Perú llega a su bicentenario sin un verdadero catastro de predios, sino con el mismo entramado institucional que existía antes de la publicación de la Ley de Catastro. Si bien ha habido avances, como la uniformización de estándares y mayor coordinación entre entidades mediante el acceso al SNCP, no se ha logrado, ni se encuentra remotamente cerca, de lograr un verdadero catastro de predios, con información detallada, actualizada y uniforme.

A su vez, la falta de un verdadero catastro de predios genera una amplia variedad de problemas para el país. En el año del bicentenario, es conveniente poner en relieve estos problemas y llamar la atención sobre la importancia de contar con un catastro de predios como herramienta para construir un mejor país.

\footnotetext{
Artículo 21 de la LSNC.

Artículo 29 del Reglamento de la LSNC.

29 Existen varios distritos que han declarado su jurisdicción como zona catastrada como el distrito de Picsi, en Lambayeque o de Casa Grande en La Libertad; sin embargo, el SNCP no ha emitido su conformidad con que se trate de zonas catastradas. La Directiva No. 002-2009-SNCP/ST establece el procedimiento para declarar una zona como catastrada, e inicia con la declaración de la entidad generadora de catastro (ej. la municipalidad) y remisión del informe a la Secretaría Técnica, quien validará y emitirá su conformidad.

30 Resolución 01-2012-SNCP-ST.

31 Resolución 02-2012-SNCP-ST.

32 Resolución 001-2014-SNCP-ST.

33 Resolución 002-2014-SNCP-ST.

34 Resolución D000001-2020-COFOPRI-STSNCP.
} 


\section{Dificultad en identificar un predio - el mayor problema en un país sin catastro}

En la segunda sección de este artículo se ha procurado delimitar una definición de catastro que lo aborde en sus distintas acepciones. Así, el catastro puede ser definido, poniendo énfasis en su naturaleza o finalidad. Esta última estará mayormente vinculada a la función de administración de bienes, mientras que en el plano legal se discute cuál es -o debería ser- la naturaleza misma del catastro. Según la normativa, el Catastro es "el inventario físico de todos los predios que conforman el territorio nacional, incluyendo sus características físicas, económicas, uso, infraestructura, equipamiento y derechos inscritos o no, en el Registro de Predios" 35 . De modo que, sin perjuicio de las distintas aproximaciones teóricas, el elemento central del catastro es siempre el mismo: la identificación de los predios y sus características.

El concepto "predio" tendrá distintas acepciones dependiendo del marco normativo consultado. Por ejemplo, la doctrina tradicional - aunque no es uniforme- equipara el predio con la parcela del terreno delimitada en su perímetro por los linderos de dicha parcela y la proyección de la misma sobre el sobresuelo y subsuelo ${ }^{36}$, a pesar de ello lo cierto es que el Código Civil no esboza una definición de "predio".

Debe recordarse que, en el plano civil, la naturaleza de los predios es estudiada desde el segmento del Derecho de las cosas, que establece una distinción entre bienes "muebles" e "inmuebles" 37 . Estos últimos son un catálogo cerrado - entre otros- que establece que los bienes inmuebles son "el suelo, el subsuelo y el sobresuelo" (artículo 885 del Código Civil). Por otro lado, aunque la palabra "predio" no se defina, sí se menciona que "la propiedad del predio se extiende al subsuelo y al sobresuelo, comprendidos dentro de los planos verticales del perímetro superficial y hasta donde sea útil al propietario el ejercicio de su derecho" (artículo 954 del Código Civil), dicho concepto coincide con el primer numeral del catálogo de Bienes Inmuebles.

Se desprende entonces, de la lectura conjunta del artículo 954 con el 885 del Código Civil, que en términos civiles el "predio" es un bien inmueble compuesto por tanto una proyección horizontal y vertical. Aquella horizontal estará delimitada por el mismo perímetro superficial del predio (los linderos y colindancias del predio),

35 Artículo 3 del Reglamento de la Ley que crea el Sistema Nacional Integrado de Catastro y su vinculación con el Registro de Predios - Ley 28294.

36 Lehmann, Heinrich, Tratado de derecho civil. Traducción José Navas. Madrid: Editorial Revista de Derecho Privado.

37 Bienes inmuebles. Artículo 885 del Código Civil.- Son inmuebles: 1.-El suelo, el subsuelo y el sobresuelo. 2.- El mar, los lagos, los ríos, los manantiales, las corrientes de agua y las aguas vivas o estanciales. 3.- Las minas, canteras y depósitos de hidrocarburos. 4.- Las naves y embarcaciones 5.- Los diques y muelles. 7.- Las concesiones para explotar servicios públicos. 8.- Las concesiones mineras obtenidas por particulares. 10.- Los derechos sobre inmuebles inscribibles en el registro. 11.- Los demás bienes a los que la ley les confiere tal calidad. 
mientras que en el plano vertical (subsuelo y sobresuelo) estará determinado en función a la utilidad que el propietario le otorgue.

Ahora bien, el Catastro se centra en la realidad física del predio, es decir, en la existencia, ubicación y descripción física del objeto (que en este caso es lo que se asienta bajo y sobre el suelo). Es así que el Catastro proporciona la sustancia física del Predio ${ }^{38}$. Bajo ese presupuesto en el marco de la normativa catastral, el "predio" es "la superficie delimitada por una línea poligonal continua y cerrada; y se extiende al subsuelo y al sobresuelo, comprendidos dentro de los planos verticales del perímetro superficial, excluyéndose del suelo y subsuelo a los recursos naturales, los yacimientos, restos arqueológicos y otros bienes regidos por leyes especiales" 39.

La ubicación y realidad física representadas por un polígono se materializa en la Cartografía generada a través de las mediciones técnicas. Es por ello que la función cartográfica es necesaria para el funcionamiento de cualquier catastro, ya que consiste en la creación y mantenimiento de las bases cartográficas en las que se representa la realidad parcelaria. Estas bases pueden tener contenido distinto según los casos, e incluir mayor o menor información, pero siempre incluyen la representación de las parcelas. En atención a ello, el Catastro se encarga de la cartografía a gran escala en la que se representa la división parcelaria ${ }^{40}$

Sin embargo, en Perú la inmatriculación predial y planificación urbana nacieron sin un desarrollo paralelo de cartografía. Por el contrario, nuestro sistema durante muchas décadas se ha basado fundamentalmente en una descripción y ubicación de los predios en forma literal o alfanumérica y no gráfica. Así, por ejemplo, ha formado parte de la descripción alfanumérica consignar el nombre de la calle o lugar de ubicación, la numeración, el nombre de los propietarios colindantes, los accidentes geográficos que rodean el predio, entre otros datos ${ }^{41}$.

Los escuetos resultados a los que se ha llegado en términos catastrales son particularmente perniciosos para el desarrollo del país. En particular, pues cualquier acción vinculada al bien - sea su enajenación, modificación, registro, entre otros - necesita como acción primigenia e indispensable que identifiquemos el mismo. Inocuo sería accionar respecto de aquello que no se conoce, sería como realizar una tarea a ciegas. Paradójicamente esto es exactamente lo que sucede al no existir un catastro. Su inexistencia enceguece cualquier actividad predial - y subsiguiente económica- vinculada a esta. La aparentemente sencilla tarea de identificar un "predio" (como una casa o un terreno), deja de serlo cuando caemos

38 Chico y Ortiz, José María. “Estudios sobre Derecho Hipotecario". Tomo I, Marcial Pons, Tercera Edición Madrid, 1994, pp. 545.

39 Reglamento de la Ley que crea el Sistema Nacional Integrado de Catastro y su vinculación con el Registro de Predios - Ley No 28294 -DECRETO SUPREMO No 005-2006-JUS

40 Castanyer, Jorge. "Panorama de los catastros europeos" En: CT Catastro, N 31, julio 1997, p. 83.

41 PORTILlO FLORES, Angélica María "El Catastro en el Perú: estudio teórico, jurídico y de gestión", Primera Edición. Palestra Editores, Lima, 2009, pp. 38. 
en cuenta de que existen distintos datos técnicos que deben ser considerados para su identificación.

Aún más complejas serán las situaciones que involucran predios con una extensión a gran escala. Por ejemplo, en el caso de la formalización de terrenos, identificación de linderos de comunidades campesinas, identificación de polígonos del área afectada por un proyecto de gran envergadura, la complejidad técnica será mayor.

Lo cierto es que aunque a la fecha el SNCP ha aprobado reciente normativa técnica en materia catastral, y se han establecido manuales de los procesos estandarizados para el levantamiento, mantenimiento y actualización de los predios urbanos y rurales, esto no ha sido suficiente para impulsar la generación del catastro en el Perú. Por lo tanto, identificar un predio sigue siendo una labor más retadora (por lo ineficiente y costosa) de lo que debería.

\section{Problemas específicos de no contar con un verdadero catastro}

Ahora bien, el problema de la identificación predial tiene distintas consecuencias. Especialmente en el plano práctico, la inexistencia de un catastro representará un continuo entorpecimiento y afectación de los intereses tanto estatales como privados. Para ponerlo en perspectiva, la identificación predial representa el primer peldaño en común de muchos procedimientos. $\mathrm{Y}$, así como no hay un "segundo escalón" sin un primero que le antecede, de la misma forma todas las situaciones que se exponen a continuación al carecer de un catastro del cual guiarse tienen que "saltarse" el escalón de la identificación predial, con todas las funestas consecuencias que esto trae, y saltar (a veces al vacío). A continuación, vale la pena conocer algunas de dichas situaciones:

\section{i. Dificultad de realizar un planeamiento territorial}

En algunas regiones, el desarrollo territorial se ha producido de formas poco organizadas, apareciendo viviendas y construcciones sin el permiso formal de las autoridades ${ }^{42}$. En dicho contexto, en los últimos treinta años se ha dado un cambio progresivo en la visión del Catastro, como una institución que debe cumplir funciones cada vez más amplias y diversas.

Esta visión fue acuñada a partir de la Agenda aprobada en 1992 durante la Conferencia de las Naciones Unidas sobre Medio Ambiente y Desarrollo, realizada en la ciudad de Río de Janeiro y de la Resolución de la Segunda Conferencia de las Naciones Unidas sobre Asentamientos Humanos - Hábitat II. Ambos documentos dejan clara la importancia de la información territorial confiable como

42 Enemark, S., Hvingel, L. T., \& Galland, D.. "Land administration, planning and human rights". Planning Theory, 13(4), 2014, 331-348. Consulta realizada el día 11 de julio de 2021 en: https:/ / doi.org/10.1177/1473095213517882 
apoyo a los procesos de toma de decisiones orientadas a preservar el medio ambiente y a promover el desarrollo sostenible ${ }^{43}$.

Teniendo esto en cuenta el Catastro se convierte en el punto de partida de un sistema de información territorial al servicio del conjunto de las diversas administraciones públicas; de las actividades privadas de las empresas y de las necesidades de la ciudadanía en general. El catastro se convierte así en un punto clave para la elaboración de planes de desarrollo, ordenamiento territorial, planeamiento urbano, protección del medio ambiente, formalización de la propiedad informal, ayudas públicas, redes de transporte, hidrografía, minería y cualesquiera otras actividades públicas o privadas en el que se requiera información territorial a nivel parcelario ${ }^{44}$.

Ahora bien, como se ha venido repitiendo a lo largo de este artículo, el catastro territorial es un inventario público que gestiona la información relativa a las parcelas de tierra. Naturalmente, una de sus más importantes virtudes recaerá en el papel clave que tiene en la planificación urbana en América Latina. Como se ha visto, un catastro multipropósito asociará a las distintas partes comprometidas a generar información extensa, detallada y actualizada sobre una ciudad reuniendo datos alfanuméricos, mapas y recursos humanos y financieros al servicio de una planificación urbana organizada ${ }^{45}$.

En el Perú, en materia de acondicionamiento territorial existen dos instrumentos clave: (i) los Planes de Acondicionamiento Territorial (correspondientes a los ámbitos urbanos y rurales, cuencas o espacios litorales); y (ii) los Planes de Desarrollo Urbano; ambos basados en material cartográfico georreferenciado con coordenadas UTM en el Datum Oficial los cuales - en teoría- deberían nutrirse del Catastro. Es así que, el mismo Reglamento de Acondicionamiento Territorial y Desarrollo Urbano Sostenible establece que el levantamiento catastral es el proceso por medio del cual se obtiene información gráfica y alfanumérica georreferenciadas, correspondiente a los predios de una determinada circunscripción territorial. De modo que, los catastros urbano, rural y minero como inventarios técnicos y descriptivos de la propiedad y las actividades económicas, constituyen fuente de información para la planificación, la gestión urbana y la tributación local, teniendo carácter de insumo para el servicio público.

Sin embargo, de acuerdo al Instituto Nacional de Estadística e Informática - INEI, a través del Registro Nacional de Municipalidades - RENAMU, sólo el 40\% de las 195 municipalidades provinciales y el 22\% de las 1,639 municipalidades distritales

43 Diego Alfonso Erba y Miguel Águila. “Aplicaciones del Catastro Multifinatario en la Definición de Políticas de Desarrollo Urbano en Latinoamérica”, p. 7, noviembre 2003. Consulta realizada el día 11 de julio de 2021 en: https:// www.lincolninst.edu/sites/default/files/pubfiles/catastromultifinalitario-politicas-de-suelo-urbano-full.pdf

44 PORTILlO FLORES, Angélica María “El Catastro en el Perú: estudio teórico, jurídico y de gestión", Primera Edición. Palestra Editores, Lima, 2009 pp. 35.

45 DIEGO ALFONSO ERBA AND MARIO ANDRÉS PIUME "Making Land Legible Cadastres for Urban Planning and Development in Latin America". Lincoln Institute of Land Policy. Massachusetts, 2018 pp. 52. 
cuentan con Planes de Desarrollo Urbano46. Aunado a ello, hasta el año 2017, solo un $55.2 \%$ de las municipalidades contaba con un catastro y de esos, solo el $20.2 \%$ (11.15\% del total) había realizado una actualización del mismo ${ }^{47}$.

En ese orden de ideas, en la actualidad al no existir un catastro implementado adecuadamente a nivel nacional, la implementación de la planificación urbana se ve mellada, pues de nuevo es planear a ciegas.

\section{ii. Superposición y/o duplicidad de bases gráficas registrales}

El Catastro y el Registro de Predios son instituciones cuyas actividades giran en tomo al ámbito predial. Sin embargo, se diferencian por las finalidades que persiguen, la información territorial que administran, los principios que les rigen, la forma de organizarse, el modo de operar y las técnicas que aplican, entre otros aspectos $^{48}$.

De modo que, mientras que el Registro de Predios tiene como finalidad esencial garantizar la protección de los derechos reales inscritos, el Catastro nació para brindar información relevante sobre la localización geográfica de los predios y sus características.

De manera que se trata de instituciones especializadas, en la que el Catastro se centra en la ubicación y descripción física del objeto (realidad física) y el Registro de Predios en el sujeto titular y los derechos que ejerce sobre el objeto (realidad jurídica) ${ }^{49}$.

Sin embargo, la poca confiabilidad de la información física de parte de los archivos del Registro de Predios, debido a la falta o baja calidad de la información gráfica que sustenta las inscripciones (mapas sin georreferenciación, descripciones vagas y texto describiendo en forma genérica los predios) se traduce en la ausencia de soporte catastral para los registros ${ }^{50}$. Ello indefectiblemente se traduce en doble inmatriculaciones o superposiciones entre los predios inscritos, lo cual podría evitarse de existir un catastro.

Como ha señalado el Tribunal Registral de Trujillo, “(...) nuestro sistema registral de predios tiene debilidades generadas principalmente por la carencia de un catastro, que impide de manera efectiva correlacionar la realidad objetiva con la realidad jurídico-registral (... $)^{51 "}$. Dichos problemas son de larga data, tomando en

46 Decreto Supremo que aprueba el Reglamento de Acondicionamiento Territorial y Desarrollo Urbano Sostenible DECRETO SUPREMO No 022-2016-VIVIENDA.

47 Instituto Peruano de Economía, "El Catastrófico Catastro Peruano". Informe de El Comercio IPE. Consulta realizada el día 11 de julio de 2021 en: https://www.ipe.org.pe/portal/elcatastrofico-catastro-peruano/

48 PORTILlO FLORES, Angélica María "El Catastro en el Perú: estudio teórico, jurídico y de gestión", Primera Edición. Palestra Editores, Lima, 2009, pp. 53.

49 Idem.

50 Idem.

51 Resolución 089-2094-SUNARP-TR-T del 19 de mayo de 2004. 
cuenta que las primeras inscripciones de bienes inmuebles datan aproximadamente desde 1889 y que carecen de planos (de los existentes, algunos no cuentan con las condiciones técnicas necesarias y otros estarían deteriorados por el transcurso del tiempo o uso). Ello ha generado diversos casos de duplicidad de partidas registrales y/o superposiciones totales, parciales, reales, físicas ${ }^{52}$.

Y es que, las debilidades de nuestro sistema de transferencia de propiedad inmueble y la falta de un catastro de bienes raíces que re-úna toda la información física relativa a cada predio inscrito, traen como consecuencia directa la inseguridad jurídica no solo de los propietarios, sino además, de los terceros que desean contratar con estos (persona natural o personas jurídicas) ${ }^{53}$.

Es así que, cualquier persona diligente - natural o jurídica- antes de adquirir un predio, tendría que descifrar si sobre el mismo existen o no superposiciones. Para tal fin dicha persona tendría como aliado a un instrumento de publicidad registral denominado "Certificado de Búsqueda Catastral" (CBC). Dichos instrumentos son de particular importancia para la identificación de los predios afectados, ya que son expedidos por la SUNARP y según el Reglamento del Servicio de Publicidad Registral son una forma de publicidad formal certificada denominada como "compendiosa", la cual es expedida por el Registrador o abogado certificador, previo informe técnico del área de catastro de la SUNARP. Así, en líneas generales, los CBC acreditan si el polígono descrito en el plano presentado se encuentra inmatriculado o si parcial o totalmente forma parte de un predio ya inscrito que conste incorporado a la Base Gráfica Registral.

Así, en palabras de Sonia Campos, ex Registradora Pública, desde hace algunos años se incorporó al procedimiento registral de inscripción la participación de las denominadas "oficinas de catastro" en cada una de las zonas registrales. La labor de estas es ser un soporte para la verificación de los aspectos técnicos de la documentación presentada al registro previa inscripción ${ }^{54}$.

Es así que, por ejemplo, si se solicita un $\mathrm{CBC}$ respecto a un predio inscrito en la Partida $\mathrm{N}^{\mathrm{a}}$ " $\mathrm{A}$ "- con el fin de identificar con qué otros predios podría superponerse- se recibirá un documento que mostrará el polígono en consulta y de ser el caso- otros que se encuentren parcial o totalmente superpuestos con el citado predio (representado por un polígono) en consulta. Lo cual gráficamente se vería así:

52 ROJAS ALVARADO, Oswaldo. "De la necesidad de una metodología de saneamiento técnicolegal de la propiedad predial”. En: Diálogos con la Jurisprudencia, No 139, 2010, pp. 305.

53 Idem.

54 CAMPOS, Sonia. “La Base Gráfica Registral y sus implicancias en la calificación e inscripción de los actos y derechos en el Registro de Predios". En: Agnito, 2018. 


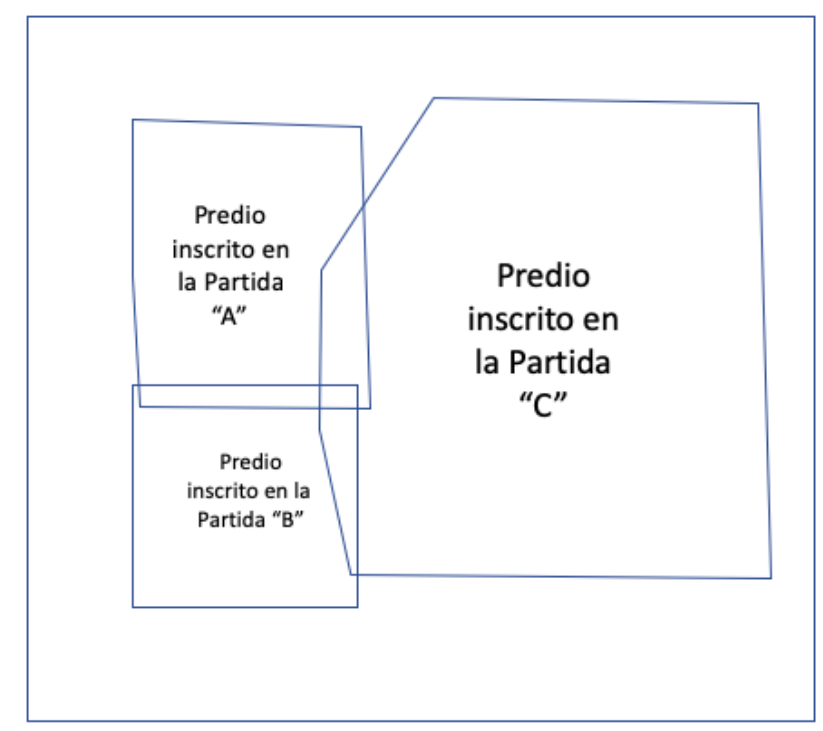

Figura 1: Elaboración Propia

Como puede notarse en la Figura 1, el Predio inscrito en la Partida "A", estaría parcialmente superpuesto con la Partida "B" y la Partida " $C$ ". Probablemente en la realidad cada uno de los titulares de los predios identifiquen que los linderos de su predio no se superponen con los de su vecino. Podrían inclusive existir construcciones en cada uno de los predios que, como es evidente, en la realidad no se "superpondrían" entre sí. Sin embargo, la realidad gráfica de registros es lo suficientemente inexacta y pobre para generar problemas incluso donde no sea evidente una disputa de linderos.

Ahora bien, inclusive si se hiciera el ejercicio de cruzar la información gráfica de nuestro $\mathrm{CBC}$ con las distintas bases catastrales, se podría encontrar el siguiente resultado gráfico: 


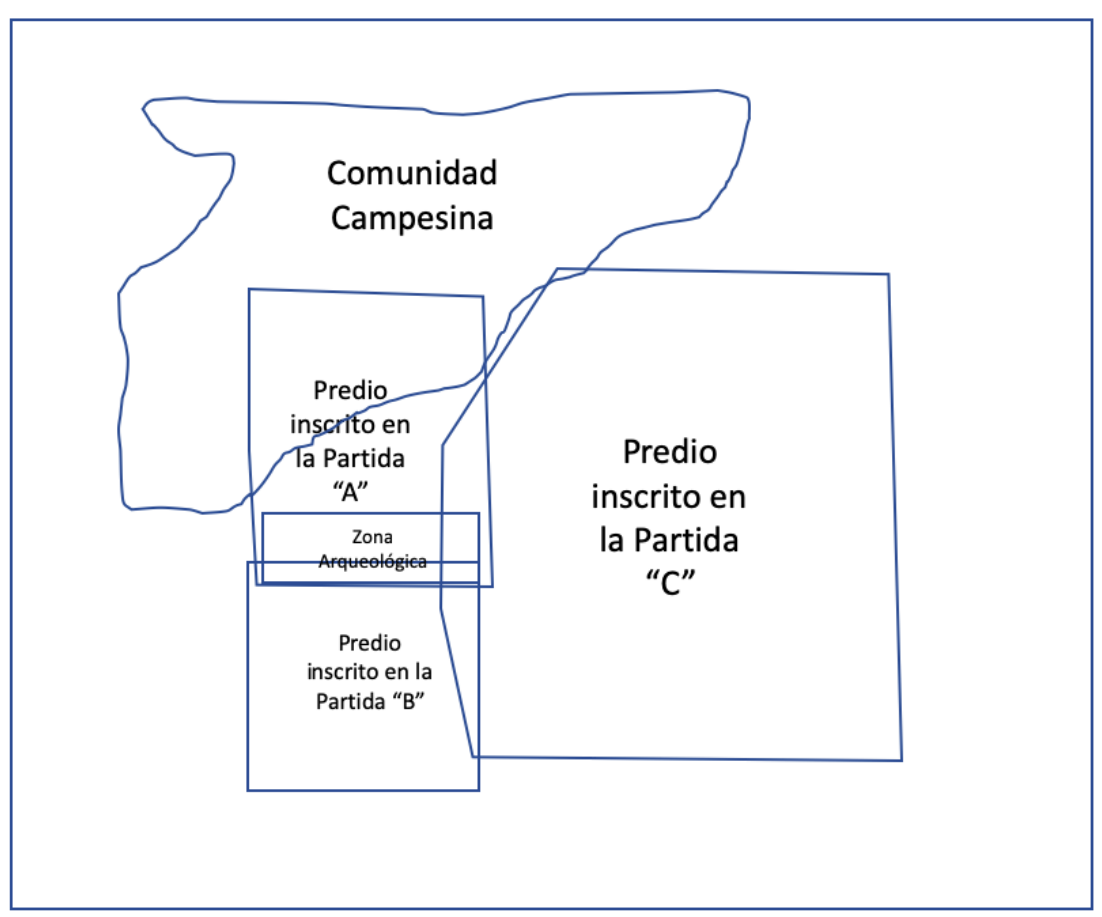

Figura 2: Elaboración Propia

Como muestra la Figura $\mathrm{N}^{0}$ 2, se podría terminar identificando que el predio A no solo se superpone parcialmente con otros predios inscritos, sino que se superpone totalmente con una zona arqueológica y parcialmente con una Comunidad Campesina.

Casos como los descritos, son el pan de cada día, y responden a la falta de catastro. Cabe recordar que SUNARP no es un ente generador de catastro, sin embargo, recopila la información gráfica que llega al registro y contrasta dicha información con aquella ya existente.

Es así como, en términos sencillos, los profesionales que integran las aludidas oficinas de catastro de SUNARP realizan una comparación entre la información que conforma cada título inscribible (que contiene un acto de incorporación o modificación de un predio) y la confrontan con la que han reconstruido en base a los datos técnicos que contienen los títulos archivados (entiéndase como tal al documento que dio mérito a una inscripción) ${ }^{55}$.

Esta situación ha sido de alguna forma reconocida a través del Noveno Precedente de Observancia Obligatoria aprobado en el Pleno Décimo Segundo del Tribunal Registral, cuya sumilla expresa que: "No impide la inmatriculación de un predio el informe del área de catastro señalando la imposibilidad de determinar si el mismo se encuentra inscrito o no".

55 Idem. 
$\mathrm{Al}$ respecto el profesor Jorge Ortiz señala lo siguiente:

"Siempre me aterró el precedente mencionado. ¿Por qué? Porque ya sabemos que en el registro no tenemos catastro, eso debería estar claro, pero no obstante ello, peor aún, se permite incorporar predios a ciegas, o mejor dicho, a la nada. Ello es como entrar a una cueva oscura y no saber que hay al final de la misma. ¿Cuál será el efecto de inmatricular un predio sin saber en dónde estará? Muy sencillo, estaremos registrando un derecho sin correspondencia física. ¿Y ello, por qué es materia de preocupación? Porque, a ese predio luego le van a aplicar en actos posteriores o desde la inscripción de ese predio inmatriculado le van a exigir a otros predios que no se superpongan con el que ingresó sin saber en dónde estaría. Creo, que dicha situación normativa desde el Precedente lo único que ha conseguido es incertidumbre, caos y conflictividad desde el registro que se supone se encuentra llamado a no generar inestabilidad. Se dice que ello es por inscripción. Esta fue una moda impuesta en un momento en nuestro registro. Es más, dicho principio registral no existe en nuestro ordenamiento civil"56.

Como puede notarse, la inexistencia de un catastro tendrá como consecuencia también la impredictibilidad jurídica, pues la información catastral no solo puede ser variante, sino dispersa. Esto se traducirá en procedimientos de cierre de partidas, rectificación de linderos e inclusive posibles disputas respecto a qué propietario cuenta con un mejor derecho de propiedad. Es por ello que es particularmente perjudicial la existencia del Tercer Precedente de Observancia Obligatoria aprobado en el Pleno Centésimo Quincuagésimo Quinto del Tribunal Registral, el cual señala que "Procede la rectificación de área, linderos y/o medidas perimétricas en mérito a escritura pública otorgada por el propietario acompañado de la documentación a que se refiere el artículo 20 del reglamento de inscripciones del registro de predios, tanto si se rectifica a área mayor o menor, siempre que la oficina de catastro determine indubitablemente que el polígono resultante se ubica dentro del ámbito gráfico del predio inscrito. Dicha rectificación no procederá cuando se afecte derechos de acreedores inscritos o medidas cautelares, salvo que los afectados o el órgano jurisdiccional o administrativo autoricen la rectificación".

La pregunta cae de madura, ¿cómo es posible hacer depender una inscripción de un inexistente catastro? La respuesta no se sabe y se puede decir - sin temor a equivocación - que tampoco la misma SUNARP lo sabe.

\section{iii. Retraso y entorpecimiento de proyectos de infraestructura}

La infraestructura pública es el conjunto de elementos, dotaciones o servicios necesarios para el buen funcionamiento de un país, o de una comunidad en general ${ }^{57}$. En tal sentido, su desarrollo consiste en la construcción de carreteras,

56 ORTIZ PASCO, Jorge. ¿Existe Catastro en Sunarp? En: Parthenon, 2020. Consulta realizada el día 11 de julio de 2021 en: http:/ / www.parthenon.pe/esp/privado/existe-catastro-en-sunarp/

57 DÍAZ-GUEVARA, Álex. "Asociaciones Público Privadas en infraestructura vial: Análisis y modelo de gestión en el Perú basado en una conceptualización antropológica". Lima: Escuela de Dirección de la Universidad de Piura, 2017. 
puentes, redes eléctricas, redes de agua potable, redes de desagües, hospitales, postas, estadios, zonas de recreación pública, teatros, aeropuertos y todo lo que ello involucra.

La infraestructura pública se diferencia de la infraestructura privada, en tanto la primera posee una finalidad esencial: satisfacción de necesidades colectivas, es decir, está destinada al uso público o al aprovechamiento general58. Por ello, la concepción misma de infraestructura pública supone la consecución de alguno de estos dos objetivos: (i) el uso común por los ciudadanos o (ii) el beneficio proporcionado por su ejecución y explotación ${ }^{59}$.

Por ello, es innegable el carácter esencial del desarrollo de infraestructura para la economía de cualquier país. Como señala el CEPAL ${ }^{60}$, la provisión eficiente de los servicios de infraestructura es uno de los aspectos más importantes de las políticas de desarrollo. Los países "siempre requieren ampliar y modernizar su infraestructura básica de acuerdo con estándares tecnológicos internacionales, lograr niveles máximos de cobertura del territorio nacional y satisfacer con eficacia las necesidades de servicios de infraestructura de los agentes económicos y las personas."

En consecuencia, el desarrollo de infraestructura pública es un factor esencial para la producción y un criterio para medir la competitividad económica de los países ${ }^{61}$. Respecto a la producción, es innegable que la inversión en infraestructura pública eleva el producto bruto interno a corto y largo plazo, sobre todo en períodos en que hay capacidad económica ociosa y cuando la eficiencia de la inversión es alta62.

Asimismo, conforme al World Economic Forum Global Competitiveness Report 201963, el Perú ocupa el lugar 88 de 141 países en cuanto a desarrollo de infraestructura pública; muy por detrás de países como Singapur o Estados Unidos, los cuales se encuentran en la cima de la lista. Peor aún, respecto del reporte emitido en el año 2018 el Perú decayó en tres posiciones en lo que concierne al índice de desarrollo de economía (en aquel entonces el reporte lo ubicaba en el puesto 85). Ello solo demuestra que la falta de desarrollo en infraestructura y la brecha existente en acceso a la misma, aún son problemas que deben ser abordados.

58 JIMENÉZ DE CISNEROS, Francisco Javier. "Hacia un nuevo concepto de infraestructura público/obra pública desligado del dominio público y del servicio público". Madrid: Universidad Autónoma de Madrid, 1999.

59 Idem.

60 ROZAS, Patricio, \& SÁNCHEZ, Ricardo. “Desarrollo de infraestructura y crecimiento económico: revisión conceptual. CEPAL", División de Recursos Naturales e Infraestructura. Santiago: Organización de las Naciones Unidas, 2004.

61 Por competitividad, nos referimos a los atributos y cualidades de una economía que permiten un uso más eficiente de los factores de producción. El concepto está basado en la teoría de la contabilidad del crecimiento, que mide el crecimiento como la suma del crecimiento en los factores de producción, es decir, trabajo y capital; y de la productividad total de los factores (TFP, por sus siglas en inglés), que mide factores que no pueden explicarse por el trabajo, el capital u otras otros. (World Economic Forum, 2019)

62 Fondo Monetario Internacional. Perspectivas de la Economía Mundial: Secuelas, nubarrones, incertidumbres. Fondo Monetario Internacional, 2014.

63 World Economic Forum. The Global Competitiveness Report 2019. World Economic Forum. 
Conforme al Instituto Peruano de Economía ${ }^{64}$ el concepto de brecha de inversión implica:

“(..) el reconocimiento de la falta de inversiones para llegar a cierta meta o para cumplir con ciertos requerimientos de infraestructura, ya sea por el uso de instalaciones en condiciones sub-óptimas y/o la dificultad de satisfacer la demanda actual y futura. Este concepto es estático debido a que no proviene de una programación de inversiones en el tiempo, sino que es un agregado del total de inversiones que se requerirían realizar para cumplir las metas establecidas. Por esta razón, el monto global que se obtiene no puede ser considerado como el valor presente de estas inversiones"

Como es señalado en la definición anterior, una brecha de inversión en el sector infraestructura supone o una insuficiencia para satisfacer las demandas de nuestro contexto o, que la infraestructura existente no cumple con las características requeridas para permitir un óptimo desarrollo social.

En dicho contexto, a través del Decreto Supremo No 345-2018-EF se aprobó la Política Nacional de Competitividad y Productividad. Esta política adopta una concepción estructuralista del concepto de competitividad y la interpreta como "la capacidad que tiene una nación para competir exitosamente en los mercados, a través de la utilización eficiente de sus recursos naturales renovables y no renovables y el aprovechamiento de sus ventajas comparativas, generando así bienestar compartido65".

Posteriormente, el 28 de julio de 2019 el Gobierno promulgó el Plan Nacional de Competitividad y Productividad 2019-2030 (PNCP), que implementó un conjunto de medidas para garantizar en el mediano y largo plazo del país una competitividad y productividad económica, a través del desarrollo de infraestructura pública.

En la misma línea, y de manera más específica en términos de infraestructura, el 28 de julio del 2019, a través del Decreto Supremo № 238-2019-EF se aprobó el Plan Nacional de Infraestructura para la Competitividad (PNIC). Con la finalidad específica de "proveer al Estado peruano de un insumo para construir una agenda de desarrollo transparente y consensuada que permita cerrar brechas claves para el desarrollo económico y social del país66".

A través del PNIC se priorizaron 52 proyectos de especial relevancia para el desarrollo del país. El valor total de los proyectos es de casi 100 mil millones de soles67; siendo que muchos de estos están relacionados con la construcción o

64 Instituto Peruano de Economía. El reto de la infraestructura al 2018: La Brecha de Inversión en Infraestructura al 2008. Lima: IPE, 2009.

65 Ministerio de Economía y Finanzas. Política Nacional de Competitividad y Productividad. Diario Oficial El Peruano. Lima, Perú, 31 de diciembre de 2018.

66 Idem.

67 Ministerio de Economía y Finanzas. Plan Nacional de Competitividad y Productividad. Diario Oficial El Peruano. Lima, Perú, 28 de Julio de 2019. 
expansión de aeropuertos, medios de transporte, electricidad, agua y saneamiento, entre otros.

Casi la mitad (46\%) de esta importante cartera de inversión se encuentra en etapa de ejecución 68 . Sin embargo, tal y como señala la exposición de motivos del Decreto de Urgencia $N^{\circ}$ 018-2019, en la actualidad, la causa más frecuente de retraso en la implementación de los proyectos de inversión está dada -en particular aunque sin ser exclusivo - en lo relacionado con la entrega de terrenos, levantamiento de interferencias, otorgamiento $\mathrm{y} / \mathrm{u}$ obtención de licencias, permisos $\mathrm{y}$ títulos habilitantes para la ejecución de los proyectos, descoordinaciones en la zonificación de las áreas para ejecutar los proyectos y la incompatibilidad entre proyectos ejecutados por una misma entidad pública o en una misma área.

En ese contexto, el Decreto Legislativo N 1192 (DL 1192) es un cuerpo normativo complejo que contiene distintos procedimientos que permiten agilizar la transferencia de los predios en favor de los proyectos de infraestructura.

Así, el DL 1192 contiene procesos de (i) Expropiación, (ii) Adquisición de predios mediante trato directo, (iii) Pago de mejoras a poseedores que no califiquen como "Sujetos pasivos", (iv) Liberación de Interferencias, (v) Transferencia interestatal, entre otras.

Sin embargo, antes de aplicar cualquiera de dichos procesos, deberá identificarse el Predio afectado por el proyecto y aunque pueda parecer que este paso peca de obvio, en la práctica la identificación de los predios que serán materia de algunos de los procesos regulados por el DL 1992 es medular.

A falta de un catastro, la individualización de los predios afectados por proyectos cuya extensión se expresa en hectáreas (como en el caso de los aeropuertos) o kilómetros (como en el caso de las carreteras) no es una tarea sencilla. Sin un catastro, las herramientas para poder identificar a los inmuebles involucrados en zonas de gran extensión como los polígonos que involucran los proyectos de infraestructura son: (i) la solicitud de la Base Gráfica de Registros Públicos respecto del polígono de afectación u obtención de un Certificados de Búsqueda Catastral (“CBC") correspondiente al polígono del proyecto; así como (ii) realizar un trabajo de campo para el levantamiento topográfico respectivo y la validación de la información contenida en la base gráfica de la SUNARP.

Solo dicha sinergia de acciones permitirá la identificación preliminar de los propietarios o poseedores, los cuales una vez identificados serán notificados respecto de la afectación de los predios por el proyecto de infraestructura. Sin embargo, es bastante penoso que el requisito del DL 1192 sea pedir un certificado catastral a una entidad que no realiza catastro en sí mismo ${ }^{69}$ y que, además, los

68 Idem.

69 Decreto Legislativo 1192: 16.1. Dentro de los diez días hábiles siguientes de identificados los inmuebles que se requieren para la ejecución de las Obras de Infraestructura, el Sujeto Activo comunica dicha situación a los Sujetos Pasivos y ocupantes del bien inmueble. 
proyectos dependan de los trabajos de campo que realicen los Sujetos Activos del proceso expropiatorio, como el MTC, quien tampoco es un ente generador de catastro. De modo que, una vez más la inexistencia del catastro genera un retraso en los proyectos de infraestructura.

\section{iv. Retraso en los procesos de formalización de la propiedad}

Desde el año 1996 COFOPRI se encuentra a cargo del proceso de formalización de posesiones informales en territorio urbano de propiedad estatal. Por su parte los Gobiernos Regionales (GORES) tienen esa labor en territorio rural. Esto implica que aquellos poseedores que no cuenten con un título de propiedad, y ocupen predios que son propiedad del Estado pueden formar parte del procedimiento de formalización de propiedad y obtener títulos de propiedad.

En consecuencia, COFOPRI y los GORES se encargan de gestionar y obtener títulos de propiedad en beneficio de los poseedores informales, siempre que se cumplan las condiciones que establece la normativa. Entre dichas condiciones se encuentra el haber iniciado la posesión o invasión de tierras desde determinado momento ${ }^{70}$ o que la tierra en la que se encuentren no cuente con ciertas características que no permitan su titulación (i.e. no se encuentre en zona de riesgo, ni en zona arqueológica, ni en territorio de comunidades campesinas, entre otros).

Precisamente al ser posesiones informales, cuyo origen se dio por invasiones de terrenos, aquellas no figuran en ningún catastro o registro sino hasta que se termine de formalizarlas. Por ello, COFOPRI y los GORES generan su propio catastro de posesiones informales, agrupando parcelas, urbanizaciones, manzanas y lotes individuales, según sea el caso.

Para generar su catastro se realiza un extenso diagnóstico técnico-legal de la posesión a formalizar, lo cual implica una serie de inspecciones de campo y recopilaciones de información con distintas entidades, incluyendo con el Registro de Predios, para verificar qué derechos existen en aquella zona. Ello porque, de existir terceros con derechos sobre las áreas a formalizar, el procedimiento se archiva, pues continuar implicaría despojar a particulares de su propiedad en favor de poseedores informales. Lo que corresponde en ese caso es

Previo a la comunicación anterior, el Sujeto Activo puede contar con el Certificado de Búsqueda Catastral o el Informe del especialista técnico del Sujeto Activo o del Verificador Catastral, cuando corresponda, tomando en cuenta la base gráfica proporcionada por la SUNARP y otras fuentes de información. La SUNARP proporciona el Certificado de Búsqueda Catastral en un plazo no mayor de quince días hábiles al Sujeto Activo. Al certificado va anexa los informes técnicos que lo sustentan, así como la información gráfica y digital correspondiente.

70 Originalmente se estableció en el Decreto Legislativo 803 que solo se iban a formalizar las posesiones informales que se constituyeron hasta el año 1996. Tras sucesivas ampliaciones, la más reciente con la Ley 31056 en octubre del 2020, están comprendidas en el proceso las posesiones que se constituyeron hasta el año 2015. 
que los poseedores entablen un juicio de prescripción adquisitiva de dominio contra el propietario o titular registral y diriman su conflicto en el Poder Judicial71.

La labor que realizan COFOPRI y los GORES se limita únicamente a predios del Estado. Con la autorización a aquellos, el Estado está realizando una suerte de cesión gratuita de sus propiedades que se encuentren poseídas informalmente y cumplan con los requisitos de las normas. Por ello, es de suma importancia tener certeza respecto a que los predios que son formalizados sean de propiedad estatal y no particular.

En ese contexto, la falta de un verdadero catastro de predios dificulta en gran medida los trabajos de formalización. El procedimiento de diagnóstico técnicolegal sería mucho más expeditivo si existiese un sistema catastral integrado y actualizado, que permita verificar rápidamente a los terceros que cuentan con derechos en una determinada área. De esta manera, se podría verificar si existe un particular que figure como propietario sea en el Registro de Predios o ante la municipalidad correspondiente, o si existiese una zona arqueológica, parte del territorio de una comunidad campesina o un área natural protegida, entre otros.

Al no existir tal catastro de predios, integrado y actualizado, se debe recolectar información institución por institución, lo cual demora el proceso y por tanto demora el acceso de los poseedores informales a un título de propiedad y todos los beneficios que ello conlleva (acceso a servicios públicos, acceso a crédito hipotecario, a inscribir su edificación, etc.).

En febrero del 2021, el Director Ejecutivo de COFOPRI indicó que existirían alrededor de 2'700,000 predios por formalizar, pero que la cifra real sea probablemente más alta72. A su vez, en el año 2019 COFOPRI logró formalizar 61,714 predios $^{73}$. Asumiendo un ritmo semejante por los siguientes años $74, y$ asumiendo que no se amplía la fecha mediante la cual se puede acceder al proceso de formalización, tomaría 43 años y 8 meses en formalizar los 2’700,000 predios.

Con un catastro de predios, es indudable que los procedimientos de diagnóstico serían más expeditivos y se lograría una mayor formalización de predios. Sin embargo, tras casi dos décadas de la publicación de la LSNC, no ha habido mayores avances en ese sentido.

71 Existe, sin embargo, un procedimiento de prescripción adquisitiva de tipo administrativo, que se da en supuestos específicos.

72 Declaraciones de Saúl Barrera Ayala, Director Ejecutivo de COFOPRI. Consulta realizada el día 11 de julio de 2021 en: https://www.gob.pe/institucion/cofopri/noticias/341190-titulos-depropiedad-de-cofopri-impediran-venta-del-terreno-formalizado-en-un-plazo-de-cinco-anos

73 COFOPRI, Memoria Anual 2019. Consulta realizada el día 11 de julio de 2021 en: https://enlaces.cofopri.gob.pe/media/10155/memoria_anual_institucional_2019.pdf

74 De acuerdo con la Memoria Anual de COFOPRI del año 2020, COFOPRI logró titular 35,352 predios. Sin embargo, tomando en consideración la disrupción generada por la pandemia del Covid-19, se realizó el cálculo usando un año sin aquella disrupción, como es el 2019. Consulta realizada el día 11 de julio de 2021 en: https://enlaces.cofopri.gob.pe/media/10338/memoria_anual_2020.pdf 
Ello a pesar de que COFOPRI, desde el año 2013, dirige la Secretaría Técnica del SNCP75, función que antes ejercía SUNARP. La Secretaría Técnica del SNCP es el órgano ejecutivo del SNCP, encargado de administrar el SNCP, así como llevar a cabo la vinculación entre el catastro y el Registro de Predios, por lo que es COFOPRI quien debe ejecutar todas las acciones que la LSNC y su reglamento ya establecieron pero que a la fecha no existen.

\section{v. Debilidad ante la lucha contra el fraude inmobiliario}

En el Perú existe hasta la fecha un serio problema de fraude inmobiliario que es difícil de combatir76. Mediante el fraude inmobiliario, "se encubre y oculta la titularidad real o las verdaderas circunstancias de los bienes inmuebles, en beneficio de determinados agentes que actúan en el sector inmobiliario y en perjuicio de terceros o de quienes invierten en la adquisición de bienes inmuebles"77. Las principales formas de fraude inmobiliario se dan mediante las falsificaciones documentarias y las suplantaciones de identidad del propietario de un predio.

No han sido pocas las noticias sobre mafias de tráfico de terrenos que cuentan entre sus filas a notarios, registradores, árbitros y funcionarios municipales, todos los cuales pueden tergiversar documentación a su favor, y en perjuicio de los verdaderos propietarios. Los ejemplos más relevantes de los últimos años son la mafia Orellana ${ }^{78}$ y la Banda de los Rucos, integrada por un ex alcalde de Chilca ${ }^{79}$.

Para combatir el fraude inmobiliario se han creado diversos mecanismos, principalmente a nivel de registros públicos, logrando diversos grados de éxito ${ }^{80}$. Existe por ejemplo el bloqueo registral81, que blinda a la partida registral por 60 días hábiles de cualquier inscripción incompatible con una minuta (es decir, con

75 De acuerdo con la Cuarta Disposición Complementaria Modificatoria de la Ley 29951.

76 Dentro de los últimos años, el delito de estafa (que engloba al fraude inmobiliario) se ha posicionado entre los tres delitos más comunes de cada período. Consulta realizada el día 11 de julio de 2021 en: INEI, Estadísticas de Seguridad Ciudadana. https://www.inei.gob.pe/biblioteca-virtual/boletines/estadisticas-de-seguridadciudadana $/ 1 /$

77 PUYAL SANZ, Pablo. "El Catastro como instrumento de lucha contra el fraude inmobiliario: el valor de referencia de mercado". En: Crónica Tributaria Num. 169/2018, Madrid, pp. 141. Consulta realizada el día 11 de julio de 2021 en: https://www.ief.es/docs/destacados/publicaciones/revistas/ct/169_Puyal.pdf

78 El Comercio Perú. “¿Quién es Rodolfo Orellana? Así funcionaba su red delictiva”. Lima, 2014. Consulta realizada el día 11 de julio de 2021 en: https:/ / elcomercio.pe/politica/justicia/rodolfoorellana-funcionaba-red-delictiva-381571-noticia/

79 Agencia Andina. "Alcalde de Chilca integraría red criminal dedicada al tráfico de terrenos y sicariato". Lima, 2017. Consulta realizada el día 11 de julio de 2021 en: https://andina.pe/agencia/noticia-alcalde-chilca-integraria-red-criminal-dedicada-al-traficoterrenos-y-sicariato661764.aspx\#: :text=La $\% 20 \mathrm{red} \% 20 \mathrm{criminal} \% 20 \mathrm{de} \% 20 \mathrm{la}$,sicariato $\% 20 \mathrm{y} \% 20$ corrupci $\%$ C3 $\%$ B3n $\%$ 20de\%20funcionarios.

80 POZO SÁNCHEZ, Julio. "¿Se acabó el fraude inmobiliario con la Ley 30313?. En: IUS360, 2015. Consulta realizada el día 11 de julio de 2021 en: https://ius360.com/se-acabo-el-fraudeinmobiliario-con-la-ley-30313/

81 Decreto Ley 18278, modificado por Ley 26481. 
un documento aún no inscrito) que se encuentra aún en proceso de protocolización ante Notario. También se creó el servicio de alerta registral ${ }^{82}$ que notifica al titular acerca de cualquier título que se pretenda inscribir en su partida registral83. De igual modo, el titular registral puede solicitar la inmovilización temporal de las partidas de sus bienes, de forma tal que se impida inscribir actos de disposición o gravamen sino hasta que el titular haya solicitado su levantamiento ${ }^{84}$. Asimismo, la Ley 30313, estableció dos mecanismos: (i) oposición al procedimiento de inscripción registral en trámite; y (ii) supuesto especial de cancelación de asientos registrales; ambas en caso se trate de un supuesto de falsificación de documentos o de suplantación de identidad.

Los mecanismos de defensa mencionados están ligados únicamente para defender la propiedad o titularidad de los predios que se encuentran inscritos en el Registro de Predios. ¿Qué sucede entonces con aquellos predios que están fuera del registro? Aquellos no cuentan con estas protecciones y son más susceptibles de caer en manos de traficantes de terrenos.

Es necesario tener en cuenta, que para la inmatriculación de un predio, es decir, para el acceso o primera inscripción de dominio de un predio en el Registro, se requieren informes favorables del área de catastro de SUNARP85, para lo cual es necesario presentar: (i) un plano catastral, o (ii) un plano de ubicación visado por la municipalidad distrital competente en caso no se trata de una zona catastrada86; debiendo en ambos casos cumplir con las especificaciones técnicas que establece la normativa.

El problema ocurre cuando existen discrepancias entre la información municipal y la base gráfica de SUNARP. Cualquier divergencia que supere el límite de la tolerancia catastral 87 , determinado por el SNCP, va a impedir que el predio acceda al Registro de Predios. Para subsanar e inmatricular el predio en tales casos, se tendría que realizar un saneamiento técnico-legal para que la información de las distintas entidades coincida.

Un saneamiento técnico-legal requiere de diversos profesionales por lo que es un proceso largo y costoso y, ciertamente, consistiría en una grave carga económica para un propietario individual. Sin embargo, las mafias de tráfico de terrenos cuentan con mayores recursos, y pueden lograr, a través de la suplantación del propietario y/o la falsificación de planos y documentos, y en contubernio con autoridades de toda clase, cumplir con la normativa e inscribir el predio a su nombre.

Si existiese un verdadero catastro de predios, no existirían estas divergencias entre las municipalidades y el Registro de Predios, ya que la información se encontraría

82 Resolución 027-2018-SUNARP-SN.

83 Fortalecida mediante Resolución No. 016-2021-SUNARP/SN.

84 Directiva 08-2013-SUNARP-SN.

85 Artículo 16 del Reglamento de Inscripciones del Registro de Predios.

86 Artículo 20 del Reglamento de Inscripciones del Registro de Predios.

87 Directiva 01-2008-SNCP. 
integrada y actualizada, y sería un reflejo gráfico de la realidad. Por lo tanto, al haber elaborado el catastro, esta discrepancia se tendría que haber solucionado previamente. Cada vez que, a raíz de discrepancias interinstitucionales, un propietario legítimo no puede acceder al registro por no poder contar con la documentación técnica, constituye un fracaso del Estado.

El gran reto es lograr que estas instituciones cooperen y sinceren su información gráfica. Hacerlo conllevaría a grandes ventajas para ambas. Por el lado del Registro de Predios, cumple su misión por la que fue creado, que es reflejar la realidad física en la realidad registral. Por el lado de la municipalidad, esta tendrá la información más exacta del predio en su jurisdicción, lo cual le permitirá planificar mejor su territorio $\mathrm{y}$ atender sus necesidades fiscales facilitando la recaudación $\mathrm{y}$ combatiendo la evasión de tributos municipales. Sin embargo, muchas veces "son las mismas autoridades municipales, vinculadas al tráfico de terrenos, las menos interesadas en tener un catastro funcional" 88 , como es el notorio caso en Chilca recientemente, y otras más.

En ese sentido, la lucha contra el fraude inmobiliario debe ser combatida con más fuerza, y para ello se debe de contar con las herramientas que permitan evitar que mafias inescrupulosas puedan traficar terrenos a expensas de las personas con menos recursos, que son aquellas que no pueden pagar un saneamiento técnicolegal a sus predios. A puertas del bicentenario, la voluntad política para emprender estas reformas es más imperativa que nunca.

\section{vi. Problemas de financiamiento municipal}

Uno de los muchos problemas por los que atraviesan las municipalidades en el Perú es su poca capacidad de recaudación tributaria. Con la excepción de Lima, en las municipalidades del país "la principal fuente de ingresos (...) lo constituye las transferencias de dinero que suministra el gobierno central" 89 . Esto implica que las finanzas municipales no dependen de las municipalidades mismas, sino de la salud económica del gobierno central.

Uno de los mecanismos con los que cuentan las municipalidades para generar recursos es el cobro del impuesto predial. De acuerdo con la Ley de Tributación Municipal90, el impuesto predial grava el valor de los predios urbanos y rústicos, es de periodicidad anual, y su cobro les corresponde a las municipalidades distritales sobre el territorio de su jurisdicción. Mientras más predios existan en el distrito, mayor será la ganancia para la municipalidad. Para saber cuántos predios se encuentran en su distrito, su valor y otras características de los mismos, es necesario contar con un catastro.

88 Instituto Peruano de Economía. El reto de la infraestructura al 2018: La Brecha de Inversión en Infraestructura al 2008. Lima: IPE, 2009.

89 Centro de Investigaciones de la Universidad del Pacífico. “Estrategia de Descentralización y Desarrollo de los Gobiernos Subnacionales en el Perú". Lima, 2001, pp. 36.

90 Artículo 8 del Texto Único Ordenado de la Ley de Tributación Municipal 
Sin embargo, de acuerdo con información de la $\mathrm{OCDE}^{91}$, la recaudación por el impuesto predial en Perú sólo corresponde a $0.2 \%$ del PBI. Esto a su vez equivale a la mitad del promedio latinoamericano $(0.4 \%)$ y a una quinta parte de los países que conforman la OCDE (1.1\%). De acuerdo con el Instituto Peruano de Economía $^{92}$, una de las explicaciones para la baja recaudación es la poca eficiencia del catastro.

La ausencia de un catastro de predios a nivel nacional es tanto causa como consecuencia del déficit financiero por el que atraviesan las municipalidades. Al tener el rol de entes generadores de catastro, son estas las que tienen la responsabilidad de generar el catastro que, pieza por pieza, corresponderá al eventual gran rompecabezas del catastro predial nacional. Sin embargo, al mismo tiempo y a raíz de ello, las municipalidades no cuentan con los recursos para poder generar y mantener sus catastros $\mathrm{y}$, por tanto, no se puede armar el catastro nacional.

Por mucho tiempo, cada municipalidad se encargaba de su propio catastro lo cual ocasionó que cada catastro sea un ente dispar y desarticulado de los demás, incluso aquellos catastros de municipalidades vecinas que puedan también tener jurisdicciones sobre un mismo predio. Cada una podía usar procedimientos, técnicas e información distinta para generar y mantener su catastro ${ }^{93}$.

Un avance de la LSNC y su reglamento fue corregir ello. Se logró establecer y uniformizar criterios para elaborar y mantener el catastro, aplicable para todas las entidades generadoras de catastro, de modo que no existirían dichas diferencias entre los catastros de las municipalidades y los de las demás entidades. Sin embargo, ello también ha implicado que la información gráfica que se generó previo a la emisión de las normas técnicas se deba de adecuar a las mismas. El resultado de ello no ha sido alentador, pues a la fecha solo cinco municipalidades cuentan con la conformidad del SNCP a su catastro.

Evidentemente, esto profundiza aún más la desigualdad entre los distritos. No es casualidad que 4 de las 5 municipalidades con catastro aprobado pertenecen a Lima Metropolitana, la única provincia cuyo presupuesto no depende de transferencias monetarias del Gobierno Central. En consecuencia, "en las diferentes localidades a nivel nacional conviven municipios sin catastro; municipios con catastros incipientes, municipios con catastro en desarrollo; y, municipios con catastros altamente tecnificados" 94 , y eso va a depender de los recursos fiscales de cada municipalidad.

91 Instituto Peruano de Economía. El reto de la infraestructura al 2018: La Brecha de Inversión en Infraestructura al 2008. Lima: IPE, 2009.

92 Idem.

93 PORTILlO FLORES, Angélica María. "El Catastro en el Perú: estudio teórico, jurídico y de gestión”, Primera Edición. Palestra Editores, Lima, 2009, pp. 79.

94 NEIRA REIMER, José Antonio. "Problemática del Impuesto Predial desde la Perspectiva del Catastro en el Perú" En: Gestión Descentralizada. Lima, 2011, pp. D6. Consulta realizada el día 11 de julio de 2021 en: 
Por ello, desde el Gobierno Central se debe dotar de recursos a las municipalidades distritales para que puedan destinarlos a la generación de su catastro, de acuerdo con las disposiciones técnicas establecidas por el SNCP. De esta manera, se rompería el círculo vicioso de no contar con recursos por no tener catastro y no tener catastro por no contar con recursos para elaborarlo.

Sin embargo, también se puede replantear la manera de armar el catastro predial nacional y el rol que cumplen las municipalidades en el mismo. Contrario a armar el catastro predial nacional desde el catastro local, se debe de considerar la opción de impulsar el catastro nacional de manera centralizada. Ello se abordará en la siguiente sección.

\section{Recomendaciones}

La situación actual del catastro en el país es resultado de la inacción y la falta de implementación de una propuesta a largo plazo para el mismo. Actualmente coexisten catastros de alcance nacional, como el catastro rural o urbano de posesiones a formalizar, así como aquellos de alcance local, como los catastros municipales.

La LSNC creó el SNCP y uniformizó datos técnicos para futuros catastros, pero mantuvo la labor de generación de catastros en las diferentes entidades generadoras de catastro. En tal sentido, el SNCP no tiene un rol activo, pues no genera un catastro, sino está a la espera que las diferentes entidades generadoras de catastro le remitan sus respectivos catastros para su aprobación.

En consecuencia, a 17 años de la publicación de la LSNC, es conveniente y oportuno plantear un cambio más enérgico al sistema catastral, de modo que se pueda acelerar la producción catastral en el país, que comprenda todo el territorio y que, a su vez, exista una dinámica correlación con el Registro de Predios.

En lo que respecta a la organización de los sistemas catastrales, existen dos tipos de sistemas: centralizados y descentralizados. En un sistema centralizado, la administración o gobierno central se encuentra a cargo de "generar y mantener el Catastro, a través de un determinado ministerio u organismo independiente, lo cual permite la generación de un solo Catastro de alcance nacional"95.

A su vez, dentro del sistema centralizado existen dos modelos de gestión diferentes: (i) desconcentrado, donde la administración central cuenta con oficinas alrededor del territorio; y (ii) participativo, donde la administración central cuenta con el apoyo de los municipios o provincias, para realizar y mantener el catastro.

http://www2.congreso.gob.pe/sicr/cendocbib/con3_uibd.nsf/520637E37796ADC8052579B500 63A1DF/\$FILE/tribmuni_11_01.pdf

95 PORTILlO FLORES, Angélica María "El Catastro en el Perú: estudio teórico, jurídico y de gestión", Primera Edición. Palestra Editores, Lima, 2009, pp. 48. 
Estos dos modelos, desconcertado y participativo, no son excluyentes, pueden coexistir juntos, como es el caso de España ${ }^{96}$.

Por el contrario, un sistema descentralizado consiste en "que la generación y conservación del Catastro está a cargo de la administración local o regional, surgiendo tantos catastros como municipios" 97 . Este a su vez tiene dos tipos de modelos de gestión: (i) autárquico, donde la administración local o regional cuenta con autonomía plena; o (ii) autónomo, donde la administración local o regional está supeditado a directivas y normas de la administración central98.

A lo largo de su historia, Perú ha contado con un sistema catastral descentralizado. Han sido las diversas municipalidades y entidades quienes han desarrollado su propio catastro para sus propios fines. Asimismo, al no contar con un ente rector para el desarrollo de sus catastros, estos gozaban de plena autonomía para la elaboración del catastro, constituyéndose en un modelo descentralizado autárquico.

Con la promulgación de la LSNC, se mantuvo un sistema catastral descentralizado, pero se cambió a un modelo autónomo, ya no autárquico. El SNCP fue constituido y estableció normas y directivas desde la administración central mediante la cual las municipalidades y demás entidades deben de sujetarse para elaborar sus catastros.

En ese orden de ideas, cabe preguntarse si mantener un sistema catastral descentralizado es conveniente, o si una mejor opción podría existir en un sistema centralizado. A continuación, se va a repasar una serie de ventajas y desventajas de realizar dicho cambio.

Entre los argumentos a favor de un sistema centralizado se encuentran:

i. Mayor capacidad financiera de la administración central, de modo que puede destinar mayores recursos a la elaboración de un catastro que las municipalidades. Ello porque al tener un mayor presupuesto, el porcentaje que representa generar y mantener el catastro es menor para el Gobierno Central. Asimismo, al elaborar un catastro nacional y no provincial, la administración central puede aprovechar de economías de escala para realizarlo a un menor costo por área.

ii. Menor desigualdad entre municipalidades con y sin catastro y/o capacidad financiera. Mantener a las municipalidades como entidades generadoras de catastro implica que ellas mismas deciden si elaborar un catastro o no. Ello puede ocurrir por falta de recursos o también por falta de voluntad política (i.e. funcionarios involucrados en fraude inmobiliario).

iii. Mayor coordinación con el Registro de Predios. Al depender la SUNARP del Gobierno Central, existiría una mayor coordinación interinstitucional entre

$96 \quad$ Ibid., pp. 50.

97 Idem.

$98 \quad$ Ibid., pp. 51. 
la autoridad catastral y el Registro de Predios. Esto contrastaría con la situación actual, donde existen tantas coordinaciones interinstitucionales como municipalidades en el país.

iv. Mayor coordinación con las demás entidades generadoras de catastro y/o bases gráficas, como COFOPRI, INGEMMET, SERNANP, entre otros; al depender todas estas entidades (así como la SUNARP) del Gobierno Central.

Entre los argumentos a favor de un sistema descentralizado se encuentran:

i. Mayor facilidad para las municipalidades en elaborar un catastro por proximidad a la zona. Sin perjuicio del costo, que puede ser prohibitivo, las municipalidades conocen mejor que el gobierno central la zona a ser catastrada.

ii. Muchos de los procedimientos que afectan la situación catastral de un predio se realizan en la municipalidad, como es el caso de independizaciones, subdivisiones y acumulaciones de predios. En ese sentido, las municipalidades tienen la información de primera mano para actualizar el catastro.

$\mathrm{Al}$ respecto, los autores de este artículo consideran que un sistema catastral centralizado es la mejor opción para elaborar y mantener el catastro predial en el Perú. Ello implicaría otorgarle al SNCP y a sus órganos respectivos, la función de elaborar y mantener el catastro predial. De esta manera, cumplirían un rol mucho más activo en el sistema catastral, pues ya no establecerán directivas que deben seguir otras entidades y quedarse esperando a que las mismas generen catastros y los remitan para su aprobación. En este escenario, sería el propio SNCP quien deba ir, municipalidad por municipalidad, a comenzar, terminar o perfeccionar el catastro predial del respectivo distrito a su cargo.

A su vez, los argumentos en contra de un sistema centralizado, arriba mencionados, son perfectamente corregibles bajo un sistema centralizado que también se rija mediante modelos desconcertados y participativos. Al tener la eventual autoridad catastral oficinas desconcertadas alrededor del territorio, se está realizando una aproximación al territorio a ser catastrado. Asimismo, al hacerlo la administración central, se cuenta con la ventaja que se realiza a un costo que no es prohibitivo, como si lo fuese en el caso de municipalidades ubicadas en distritos que pueden no contar con la capacidad técnica o financiera para levantar su catastro.

Por otro lado, al ser un modelo centralizado, pero también participativo, no se está relegando el rol de las municipalidades en el proceso de gestión catastral. Las municipalidades son precisamente las entidades más próximas a los territorios catastrados. Respecto a la elaboración del catastro, son las municipalidades mismas las que proporcionarían la información necesaria, cuánta sea que tengan, a la autoridad catastral central para que esta última realice la labor catastral, la 
misma que podría contar con participación de funcionarios de la municipalidad que puedan facilitar el trabajo de campo o disipar dudas en el proceso. Respecto al mantenimiento del catastro, las municipalidades cumplirían con notificar a la autoridad catastral respecto de cualquier acto que implique modificación en los planos catastrales, ya sea por algún procedimiento de independización, subdivisión o acumulación de predios, o para reportar el cambio de titularidad catastral.

La descentralización del país es una realidad que se impulsó con fuerza en los últimos 20 años y no es el objetivo de este trabajo hacer una evaluación de si ha funcionado o no. Lo que sí es preciso para efectos de este artículo es determinar, respecto a la función catastral, cuándo la descentralización produce resultados óptimos y cuándo no, y en estos últimos casos, si es conveniente realizar ajustes, con aras de priorizar la ejecución de la función catastral misma.

En ese sentido, centralizar la función catastral ayudaría a que las municipalidades puedan cumplir mejor sus funciones descentralizadas encargadas por ley, como la recolección de tributos y la planificación de su territorio. En consecuencia, no se les estaría reduciendo sus funciones con ánimos de restarle importancia o fuerza a los gobiernos locales, sino por el contrario, para coadyuvar una mejoría en la gestión municipal, de modo que no tengan que depender de las finanzas del Gobierno Central, como hacen hoy en días todas las municipalidades salvo la MML.

Este sistema catastral propuesto (centralizado, desconcentrado y participativo) es muy similar al sistema catastral que existe hoy en día en España. Este país cuenta virtualmente con todo su territorio catastrado, y existe una correlación dinámica con el Registro de Predios, utilizando la denominada referencia catastral (similar al Código Único Catastral regulado en la LSNC) ${ }^{99}$. La función catastral la realiza la Dirección General de Catastro salvo en las comunidades autónomas de Navarra y el País Vasco ${ }^{100}$, cuyo encargo reside en dichos gobiernos regionales.

$\mathrm{Al}$ igual que en Perú hoy en día, España también sufría una baja recaudación fiscal por parte de sus municipios en los años noventa101. Precisamente, una de las razones para explicar la mejora significativa en la salud fiscal de las municipalidades hoy en día es la concentración de la actividad catastral en la

99 PORTILlO FLORES, Angélica María “El Catastro en el Perú: estudio teórico, jurídico y de gestión”, Primera Edición. Palestra Editores, Lima, 2009, pp. 126.

100 CAVA DE LLANO Y CARRIÓ, Luisa, "La Realidad Catastral en España: Perspectiva del Defensor del Pueblo". Madrid, Defensor del Pueblo, 2012, pp. 7. Consulta realizada el día 10 de julio de 2021 en: https://www.defensordelpueblo.es/wp-content/uploads/2015/05/2012-03La-realidad-catastral-en-Espa \% C3\%B1a-desde-la-perspectiva-del-Defensor-del-Pueblo.pdf

101 MIRANDA HITA, Jesús. “El Catastro y el Impuesto sobre Bienes Inmuebles”. En: CT Catastro No. 50, Madrid, 2004, pp.8-9. Consulta realizada el día 10 de julio de 2021 en: http://www.catastro.meh.es/documentos/publicaciones/ct/ct50/_1E.pdf 
Dirección General del Catastro, que depende del Ministerio de Economía y Hacienda español ${ }^{102}$.

Un aspecto resaltante de la normativa catastral española que es conveniente mencionar es la obligación de entidades como notarías, registradores, municipalidades, entre otras, de comunicar a la Dirección General de Catastro acerca de cualquier acto que involucre una modificación en el catastro predial ${ }^{103}$. De este modo, es posible mantener el catastro predial actualizado y, asimismo, simplificar la carga administrativa al ciudadano.

Como idea final en esta recomendación de centralizar la actividad catastral, conviene mencionar una idea que va más allá del catastro, y es inspirada en el sistema registral alemán, y adoptado por varios países de la región, como Chile y Brasil. El catastro alemán es considerado uno de los catastros más confiables del mundo104105. A diferencia de Perú o España, donde el Registro de Predios es declarativo, es decir, no constituye un requisito para transferir la propiedad inscribir la misma en el registro, en Alemania el Registro de Predios es constitutivo de propiedad, es decir, constituye un requisito indispensable inscribir la transferencia de propiedad para que esta sea válida.

Sin zambullirse en un debate sobre la pertinencia de modificar el artículo 949 del Código Civil, que norma la transferencia de propiedad inmueble en el Perú, consideramos positivo contemplar la posibilidad de cambiar el Registro de Predios en el Perú a uno constitutivo una vez que se haya desarrollado un catastro predial a nivel nacional, con alta correlación con el Registro de Predios. La reticencia a cambiar el modo de transferencia hoy en día es entendible, pues existe una desactualización catastral, y en menor medida registral, de las titularidades actuales, y aún mucha informalidad en cómo se transfieren las propiedades en el país.

Sin embargo, con un catastro eficiente, correlacionado con el Registro de Predios, el margen de error entre la realidad y la información registral se reduciría considerablemente. En ese escenario, un registro constitutivo de propiedad sería más conveniente pues brindaría mayor seguridad a los compradores, quienes sabrían con certeza si están contratando con el dueño de la propiedad o no.

\section{En tanto no haya catastro, ¿qué hacer? Un paliativo temporal}

En tanto no exista un catastro de predios en el Perú, los proyectos de infraestructura continuarán retrasándose por falta de entrega de terrenos,

102 Antes existían los denominados Consorcios, entidades descentralizadas que al igual que las municipalidades en Perú previo a la promulgación de la LSNC, operaban de manera no uniforme.

103 PORTILLO FLORES, Angélica María "El Catastro en el Perú: estudio teórico, jurídico y de gestión", Primera Edición. Palestra Editores, Lima, 2009 pp. 126.

104 DEGEL, Björn. "Reliability Aspects of the German Cadastre". Vienna, 2018, presentado en la "Joint Conference of PCC and Eurographics" de fecha 21 de noviembre de 2018.

105 Sin perjuicio de ello, cabe mencionar el catastro alemán es uno de los pocos catastros europeos descentralizados, teniendo cada estado una oficina catastral. 
persistirán las superposiciones en el Registro de Predios y las municipalidades continuarán sufriendo una baja recaudación tributaria. Sin perjuicio de aquello, existen formas de lidiar con la realidad actual y sacar grandes proyectos adelante.

Para llevar a cabo grandes proyectos, entendido para este asunto como proyectos que involucran varios predios o pocos predios de grandes dimensiones, es necesario identificar los predios y determinar el grado de afectación a los mismos por parte del proyecto. A falta de un catastro, lo que corresponde es realizar un diagnóstico técnico-legal (también llamado diagnóstico físico-legal).

El diagnóstico técnico-legal difiere de un mero estudio de títulos o due diligence, que se realiza antes de adquirir un predio individual ya identificado, en tanto requiere de un análisis más allá del legal. No basta con determinar si el titular registral o municipal de un predio es realmente el propietario del mismo, o si existen cargas o gravámenes que vayan a limitar el futuro uso o disposición del predio; sino se requiere determinar y analizar la ubicación exacta del predio. Para ello, además de abogados, se debe de contar con un equipo de topógrafos e ingenieros especializados en catastro.

Diversas entidades públicas cuentan con manuales, guías o directivas que contienen los pasos a seguir al realizar un diagnóstico técnico-legal del área de afectación del proyecto. Entidades como el MTC se responsabilizan por la expropiación y/o entrega de terrenos en varios contratos públicos, y entidades como COFOPRI deben de determinar el área a formalizar y asegurarse que solo se encuentre en propiedad estatal. En estas guías, se establece la formación de equipos llamados "brigadas", conformados por abogados, ingenieros, topógrafos y otros profesionales a cargo de realizar el diagnóstico.

A grandes rasgos, un procedimiento de diagnóstico técnico-legal de un área afectada consiste en lo siguiente ${ }^{106}$ :

i. Conformación de la brigada a cargo.

ii. Levantamiento topográfico del área afectada y georreferenciación de la misma.

iii. Recopilación de información interna y externa a diferentes entidades públicas y privadas. Esto implica remitir y revisar una serie de oficios requiriendo información y recibiendo las respuestas.

iv. Elaboración de planos temáticos preliminares. Ello implica graficar la información recopilada de las entidades (propiedades inscritas, no inscritas, zonas arqueológicas, zonas de riesgo, ejes viales, etc.) en un mosaico.

v. Realización de inspecciones de campo, a fin de determinar y corregir de ser el caso, cualquier inconsistencia entre la información documentaria/gráfica y la realidad.

106 El recuento del procedimiento se ha hecho en base a guías o directivas aprobadas por entidades públicas, entre ellas la Resolución Ministerial No. 019-2018-MINAGRI, la Resolución de Secretaría General No. 027-2015-COFOPRI/SG y el Manual de Gestión de Procesos y Procedimientos (Gestión Predial) del MTC (MTC-MGPP-M.03.02.06). 
vi. Procesamiento y análisis de la información. Incluye realizar un análisis civil, registral, urbanístico, volver con las entidades consultadas, entre otros.

vii. Elaboración y estudio del informe de diagnóstico técnico-legal.

Como se puede observar, este "paliativo temporal" de realizar un diagnóstico técnico-legal completo a falta de un catastro de predios implica un elevado costo, que no puede ser asumido por muchos, y que, en un mundo ideal con catastro, no debería existir.

Hay varias razones por las que es el Estado quien se obliga a realizar el diagnóstico técnico-legal en los contratos con los privados y no estos últimos. En primer lugar, esta obligación suele venir acompañada con la obligación de expropiar los terrenos dentro del área de afectación, potestad que un privado está imposibilitado de realizar. Asimismo, el Estado, en principio, cuenta con mayor acceso a información predial, ya sea internamente o a través de mecanismos de coordinación entre entidades.

Esto también se justifica en razones de índole económicas, con o sin un contrato con un privado. El Estado, a diferencia de un privado, salvo que esté obligado contractualmente, no sufre presión de tiempo, "nunca quiebra" y está obligado como parte de sus funciones a realizar un diagnóstico técnico-legal. Un privado, por el contrario, cuenta con menos tiempo en la etapa de diagnóstico, ya que precisamente sí puede quebrar, especialmente si la etapa de diagnóstico demora mucho, ya que esta etapa por sí sola no genera ingresos; y cuenta con el costo de oportunidad de realizar otras inversiones que no impliquen este gran uso de tiempo y recursos.

Sin embargo, nada obsta que pueda existir un proyecto lo suficientemente grande que justifique el elevado costo de realizar un diagnóstico técnico-legal por parte de un privado. Por ello, resultaría conveniente transparentar más la información predial que manejan las diversas entidades, de modo que pueda ser accedida, de manera célere y sin mayores trabas burocráticas, por personas interesadas en la misma. Ello además facilita la elaboración de un eventual catastro predial, el cual sigue siendo indispensable para potenciar la actividad económica en el país.

\section{Conclusiones}

Contar con un catastro a nivel nacional y actualizado es una labor fundamental para modernizar el aparato estatal. Desafortunadamente, los intentos para crear este catastro se quedaron en retórica y normas no aplicadas, y no se le ha dado la importancia que se merece.

El principal problema de no contar con un catastro es la inhabilidad de no poder identificar un predio a través de otros medios más eficaces. De ahí se desprende toda la serie de problemas que se han presentado en este artículo. La dificultad en realizar un planeamiento territorial se da porque la falta de un catastro obliga a las 
entidades a planificar su territorio a ciegas, sin poder identificar qué predios se encuentran en su territorio. Asimismo, la falta de identificación de predios en el Registro de Predios conlleva a la existencia de superposiciones registrales, generando litigios entre titulares registrales que se proclaman dueños de la parcela física. A gran escala, esto impacta en la ejecución de grandes proyectos de infraestructura por la inhabilidad de identificar los predios involucrados.

No contar con un catastro, también representa un fuerte obstáculo para que un predio ingrese al registro. Esto debilita mucho la lucha contra el fraude inmobiliario y retrasa los avances en la formalización de viviendas. Mientras más predios se encuentren dentro del Registro de Predios, y este último esté estrechamente vinculado al catastro, se reduce el universo de predios que puedan ser objeto de fraude por parte de grupos criminales. Asimismo, mientras más fácil y seguro sea el acceso al registro, los procesos de formalización podrán ser acelerados y abarcar cada vez más predios. Finalmente, mientras más exacto sea el catastro, más eficientes serán los procedimientos de recaudación municipal, pues las municipalidades podrán identificar con mayor exactitud los predios en su jurisdicción para el adeudo del impuesto predial. Esto fortalecerá la labor general de las municipalidades y se reducirá su dependencia económica del Gobierno Central.

Se debe aprovechar la conmemoración del bicentenario de la independencia para tener las conversaciones necesarias a fin de lograr modernizar - y formalizar - el aparato estatal. La necesidad de contar con un catastro predial y los varios problemas que generan la falta de este no son abordados con frecuencia ni en los titulares, ni en la academia, por lo que este artículo ha pretendido explicar esta problemática en aras de contribuir a la conversación e incentivar la creación de un catastro predial, y se presenten propuestas concretas que no se queden en una o varias normas.

También se debe de reconocer que contar con un catastro predial no es la propuesta más atractiva electoralmente. Muchas personas que hoy se benefician de que sus propiedades no se encuentren catastradas se benefician de esta informalidad, al pagar menos tributos municipales. Sin embargo, como muchas reformas, contar con un catastro resulta imprescindible para lograr un Estado más eficiente y dinámico. Esperemos que el nuevo gobierno a instalarse este 28 de julio le de la importancia que se merece al catastro. 